NBSIR 85-3129

\title{
Standards Committee Activities of the National Bureau of Standards 1984 Highlights
}

Karl G. Newell, Jr.

U.S. DEPARTMENT OF COMMERCE

National Bureau of Standards

Office of Product Standards Policy

Gaithersburg, MD 20899

March 1985

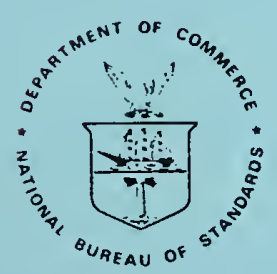

U.S. DEPARTMENT OF COMMERCE

$-Q C$

ITIONAL BUREAU OF STANDARDS

100

, 456

$85-3129$

1935

c. 2 

NBSIR $85-3129$

$\ldots$

STANDARDS COMMITTEE ACTIVITIES OF THE NATIONAL BUREAU OF STANDARDS 1984 HIGHLIGHTS

Karl G. Newell, Jr.

U.S. DEPARTMENT OF COMMERCE

National Bureau of Standards

Office of Product Standards Policy

Gaithersburg, MD 20899

March 1985

U.S. DEPARTMENT OF COMMERCE, Malcolm Baldrigo, Secretary NATIONAL BUREAU OF STANDARDS. Emeat Ambler, Diroctor 
: 


\section{ABSTRACT}

This report summarizes NBS standards committee activities and accomplishments during calendar year 1984. It profiles NBS staff participation on standards committees and highlights significant technical and individual contributions made by NBS staff. In 1984, 444 staff members (28\% of NBS' professional, scientific, and technical staff) participated in 1,138 committees of 89 national and international standards organizations.

Key Words: Annual report; committee participation; standards committees; voluntary standards. 


\section{CONTENTS}

\section{PAGE}

Abstract $-1-1.0 .0-1$

Introduction -

Summary of Participation

Organizational Highlights - 9

Awards - 39

Appendix I - NBS Form 83 -

Appendix II - List of Acronyms/Abbreviations _................... 45 


\section{INTRODUCTION}

This report summarizes NBS participation in and contributions to national and international standards organizations during calendar year 1984. The report contains two major sections:

1) a statistical summary of NBS staff activities and

2) highlights of significant contributions and accomplishments by NBS staff.

The information contained in this report was obtained through data collected by the staff of the Standards Assistance and Management Information project, using responses given on the NBS form 83, Record of Committee Assignment (See Appendix I). The form, which is completed for each committee activity by NBS staff enables NBS to maintain a complete record of staff participation on standards committees. SAMI maintains a computerized data base on these activities. The material included in the organizational highlights section was submitted by the NBS organizational units concerned.

During 1984, some 444 NBS staff members participated in activities of domestic and international standards bodies. This report identifies many of these individuals and their accomplishments. It is directed for use by NBS managers and to outside standards bodies and indicates the many individual contributions of NBS staff to national voluntary standards.

In addition to participation in outside standards bodies, the highlights section of the report covers activities dealing with other standardization activities, such as the development of Law Enforcement Standards and Federal Information Processing Standards.

Participation in standardization activities provides NBS with an important avenue for dissemination of research. In turn, involvement of NBS personnel in standardization activities provides vital information on the Nation's measurements needs in such areas as public health and safety, economic development, and'environmental protection. Standardization activities provide not only an outreach program, but also afford NBS scientists and engineers with an effective mechanism for interacting with their counterparts in industry and academia. 


\section{SUMMARY OF PARTICIPATION}

\section{Introduction}

In 1984, 444 staff members ( $28 \%$ of NBS' profes sional staff) participated on 1,138 standards committees of 89 standards organizations.

The number of committees on which memberships were held increased by 149 (15\%) to 1,138 in 1984, and the memberships held increased by 30 to 1,434 .

\section{Highlights of Participation}

Listed below are the highlights of the data collected by the SAMI project.

- The number of participants has declined over the last four years by 6 percent, while the percentage of NBS staff participation has declined by only 1 percent (see Figure 1 ).

- The major change in staff participation in 1984 was a 15\% increase in the number of committees on which NBS staff participated. This revises the downward trend of the last two years, but does not regain the 1981 level. (see Figure 2).

- While the total number of memberships held by NBS participants declined from 1981 to 1983 (from 1481 to 1404), in 1984 the total number increased by 30 to 1434 , and the number of memberships per participant increased from 3.15 to 3.23 from 1983 to 1984 (see Figures 3 and 4 ).

- The distribution of memberships by level (main committee, subcommittee, and working group) has remained virtually unchanged over the last four years (see Figure 5 ).

- The average committee tenure in 1984 was 7.4 years--up from 6.5 years in 1983. The longest committee assignment was 36 years (see Figure 6).

\section{NBS Organizational Units}

- The Center for Building Technology had the largest number of participants with 51 (representing 51 percent participation) (see Table 1).

- The Center for Fire Research had the highest number of memberships per participant with 5.13 (see Table 1). 
- The Center for Building Technology, had the largest number of committee memberships with 188 (based on 3.69 memberships per participant) (see Table 1).

\section{Outside Standards Organizations}

- Fifty-one percent of all NBS memberships were on committees of one standards organization--ASTM (see Figure 7).

- Nine standards organizations accounted for eighty-two percent of NBS committee memberships (see Figure 7 ).

- The largest percentage of committee memberships were in the form of "member" (71 percent) of a "subcommittee" (43 percent) (see Figures 5 and 8$)$.

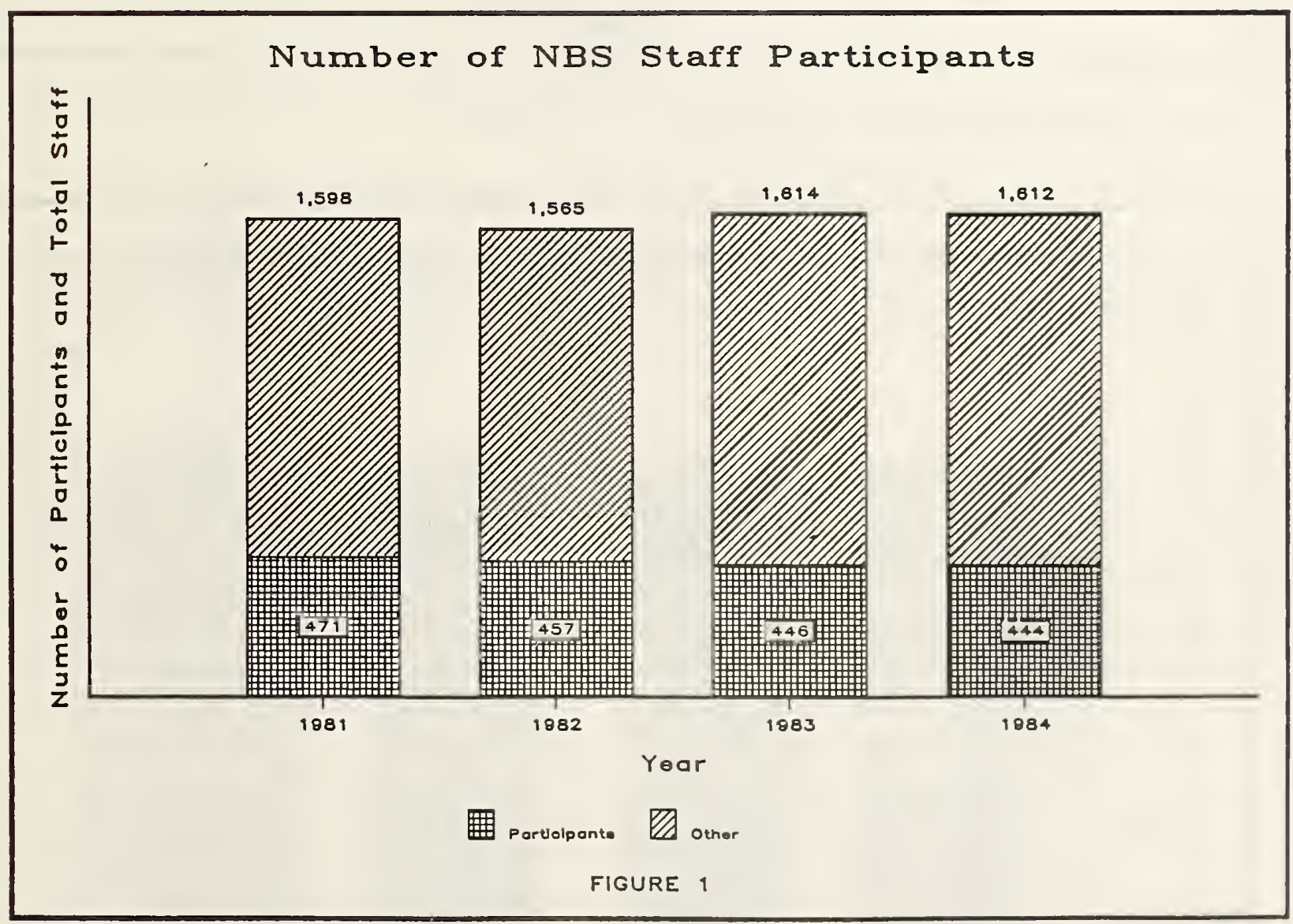



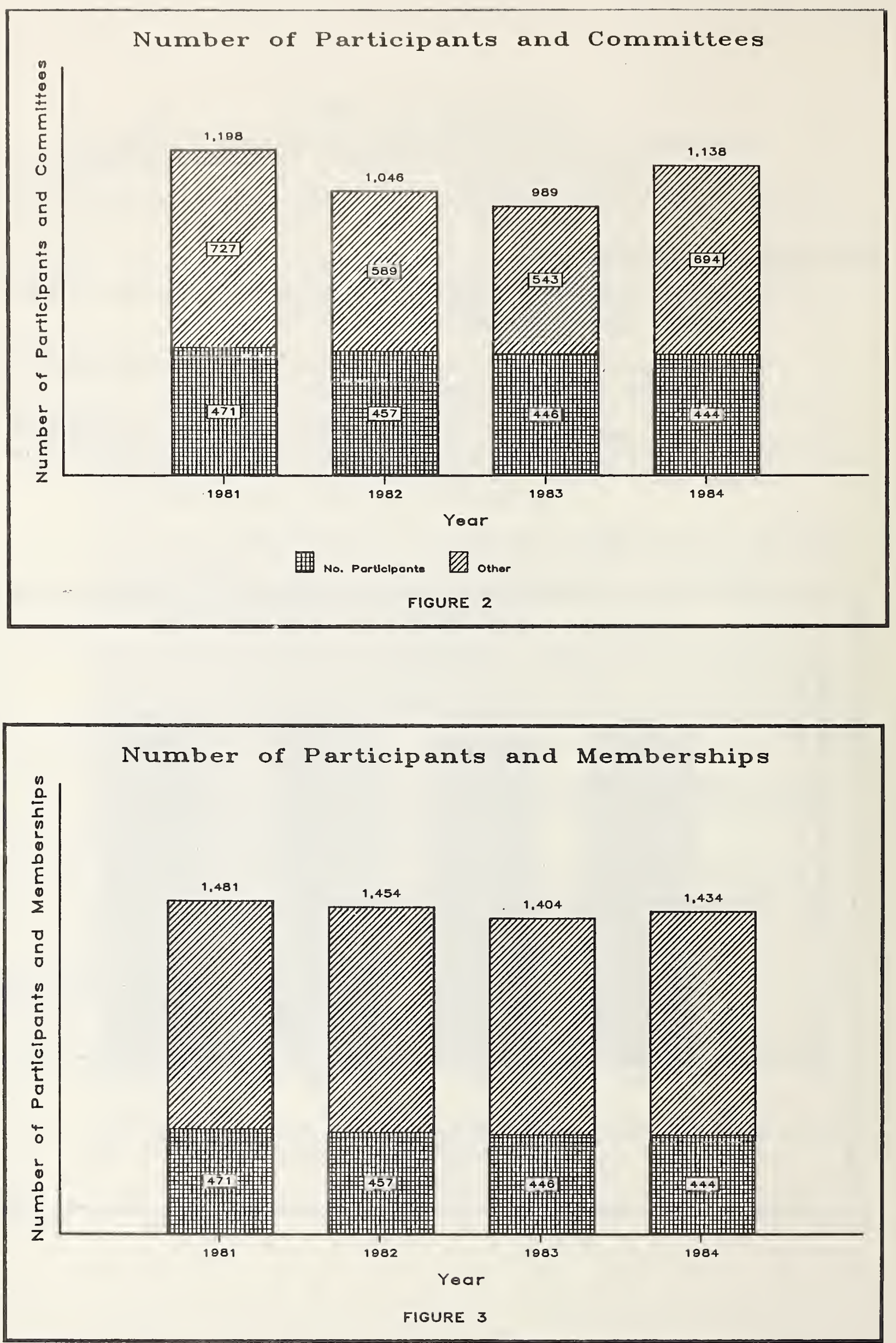
Memberships Per Participant

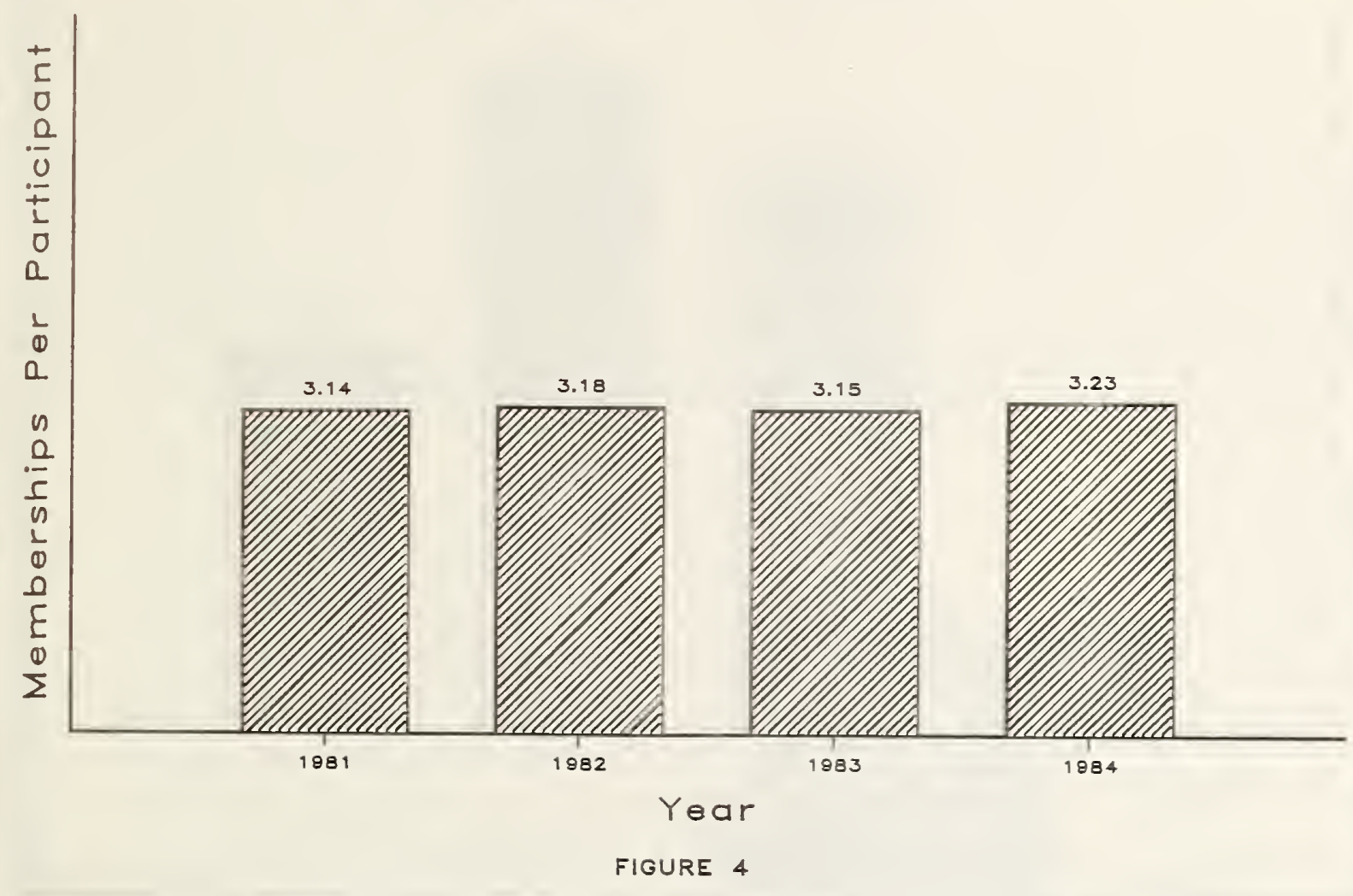

Number and Percentage of Memberships by Committee Levels

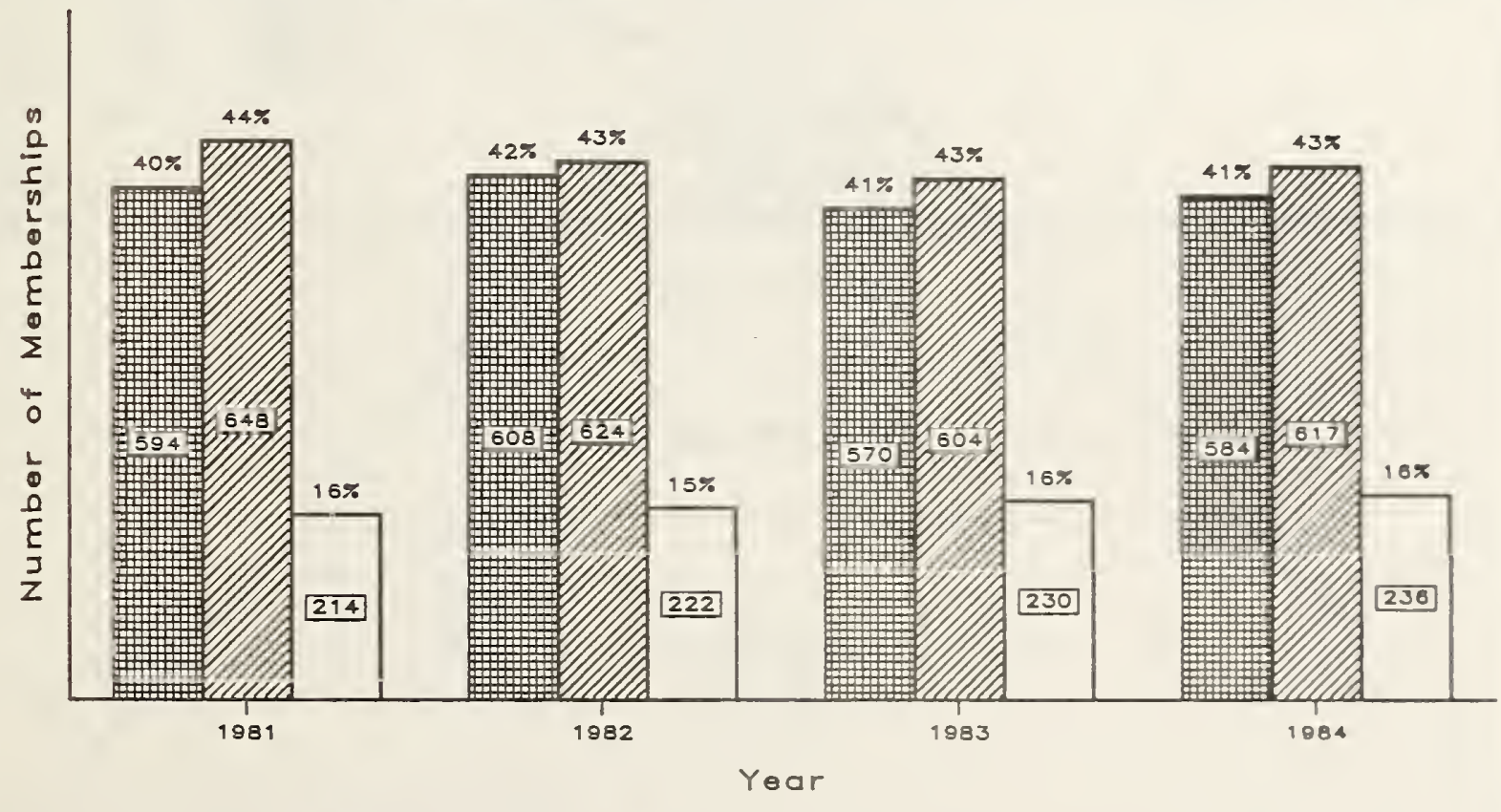

雷 Moin Committoo

Percentage of Memberships Indlcated of Top of Bar

FIGURE 5 


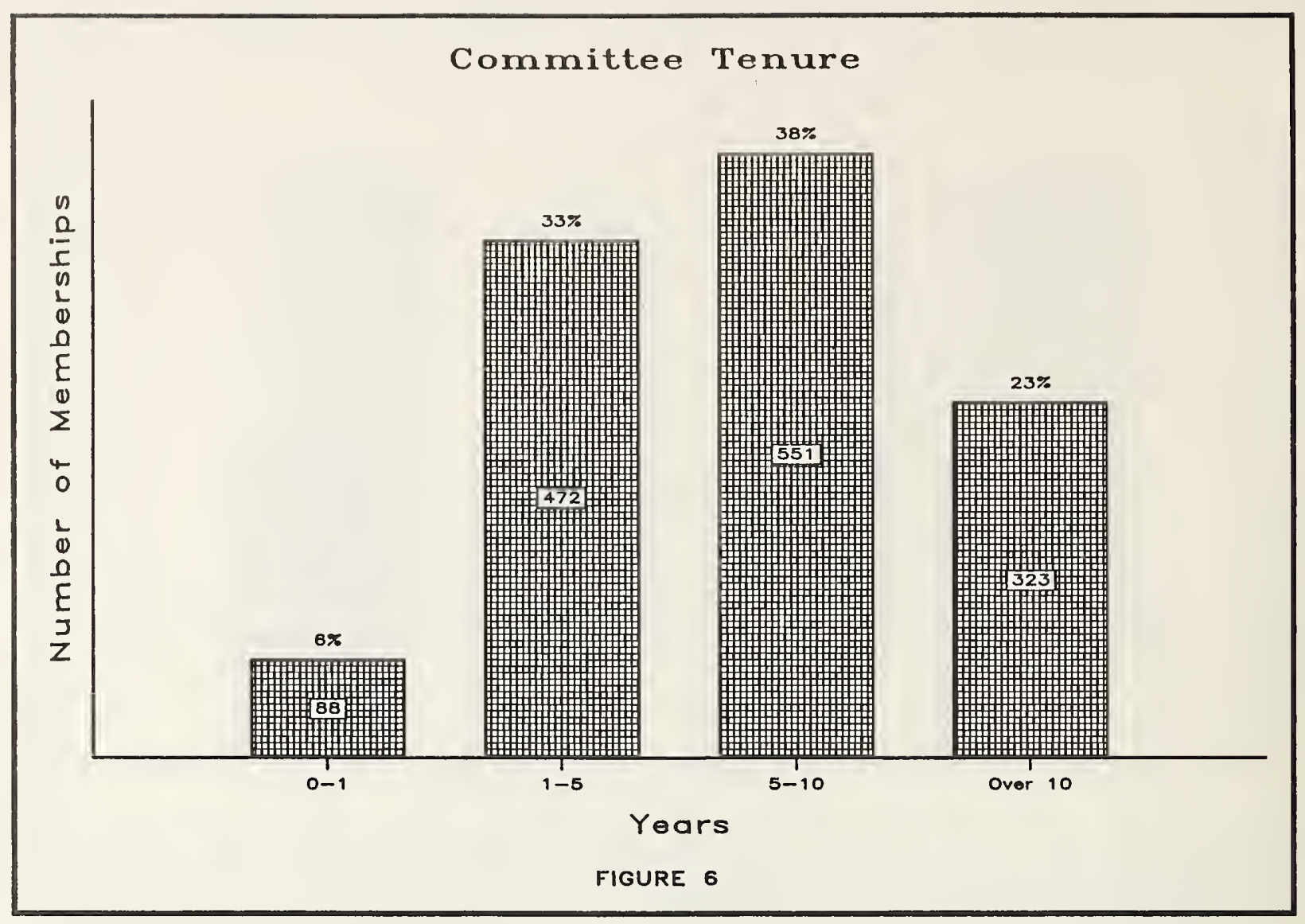

Number and Percentage of Memberships by Outside Standards Organizations

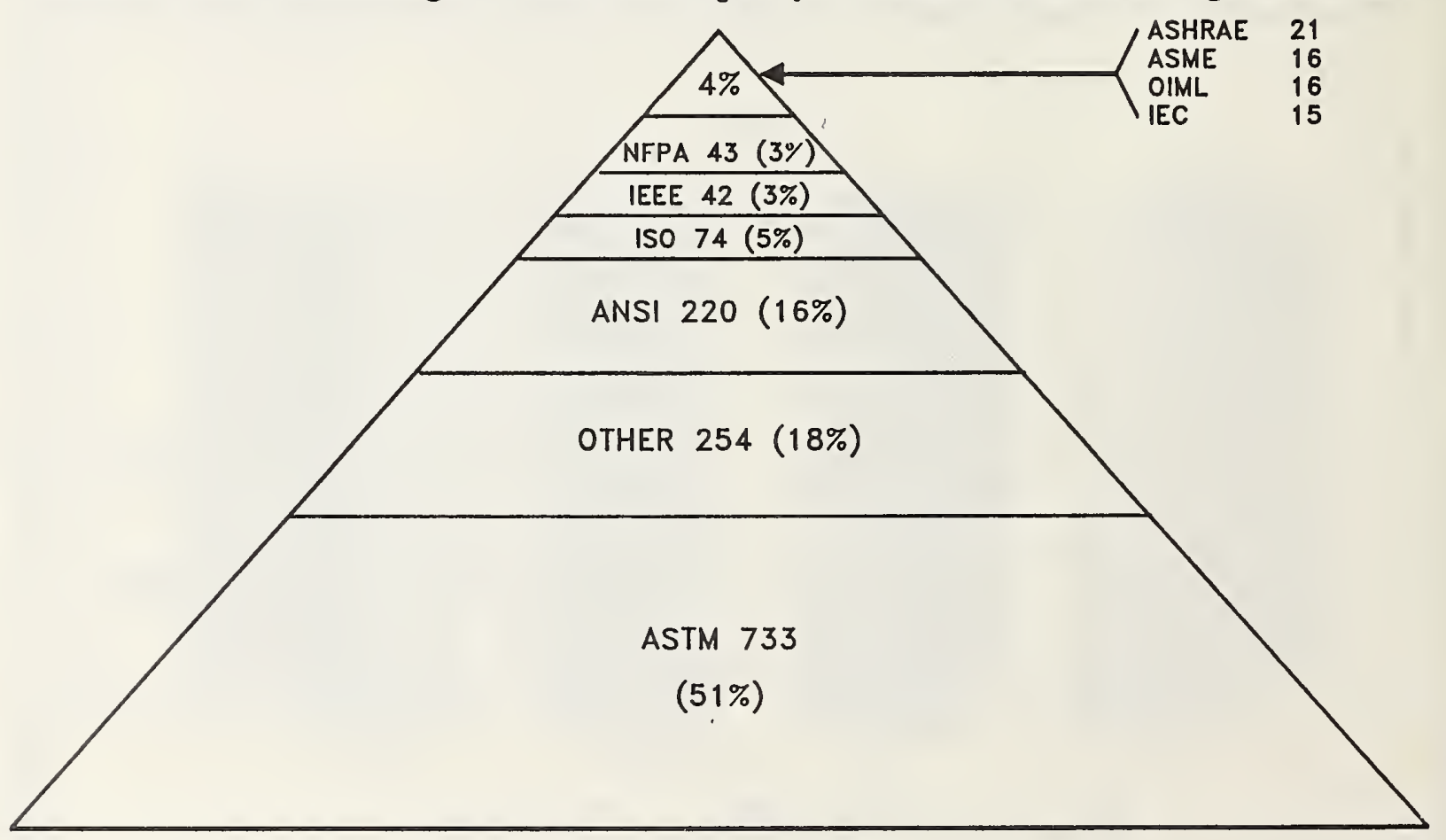

FIGURE 7 


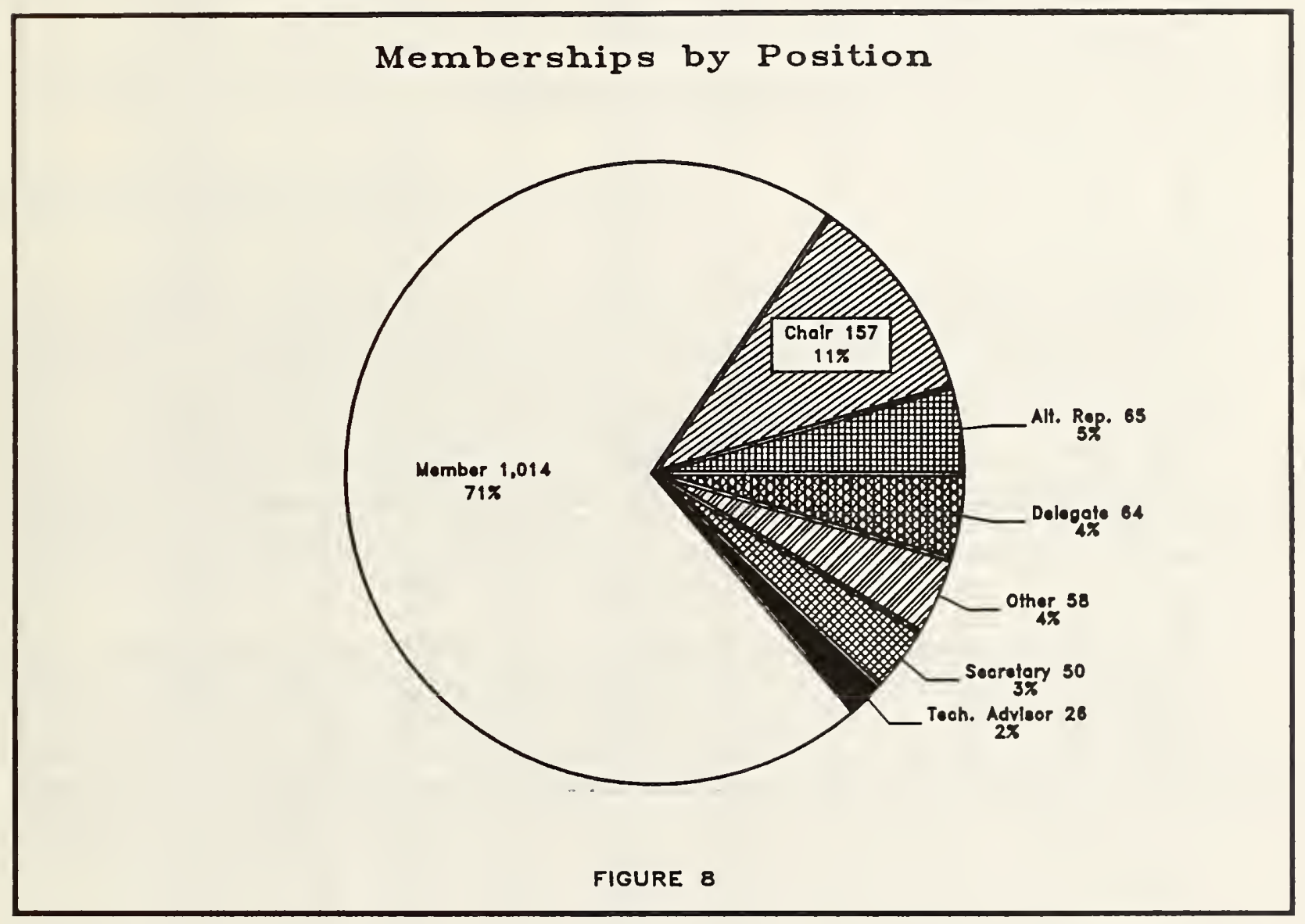


TABLE 1

Organizational Unit Participation

\begin{tabular}{|c|c|c|c|c|c|c|}
\hline & - & $\underset{\star}{\operatorname{Staff}}$ & Participants & $\frac{\%}{\text { Participation }}$ & Memberships & $\begin{array}{l}\text { Memberships } \\
\text { Per Participant }\end{array}$ \\
\hline $\begin{array}{l}\quad \text { CMS } \\
\text { IMD } \\
\text { FDD } \\
\text { PD } \\
\text { MD } \\
\text { RRD } \\
\text { OTHER } \\
\text { TOTAL C }\end{array}$ & $\begin{array}{l}420 \\
430 \\
440 \\
450 \\
460 \\
400 \\
\text { CMS }\end{array}$ & $\begin{array}{r}54 \\
25 \\
48 \\
55 \\
31 \\
10 \\
223\end{array}$ & $\begin{array}{r}18 \\
12 \\
13 \\
29 \\
2 \\
3 \\
77\end{array}$ & $\begin{array}{r}33 \% \\
48 \% \\
27 \% \\
53 \% \\
6 \% \\
30 \% \\
35 \%\end{array}$ & $\begin{array}{r}61 \\
30 \\
46 \\
102 \\
4 \\
13 \\
256\end{array}$ & $\begin{array}{r}3.39 \\
2.50 \\
3.54 \\
3.52 \\
2.00 \\
4.33 \\
3.32\end{array}$ \\
\hline $\begin{array}{l}\quad \text { NML } \\
\text { MS } \\
\text { CBS } \\
\text { CRR } \\
\text { CCP } \\
\text { CAC } \\
\text { OTHER } \\
\text { TOTAL N }\end{array}$ & $\begin{array}{l}510 \\
520 \\
530 \\
540 \\
550 \\
500 \\
M M L\end{array}$ & $\begin{array}{r}18 \\
119 \\
154 \\
66 \\
96 \\
27 \\
480\end{array}$ & $\begin{array}{r}10 \\
19 \\
34 \\
19 \\
35 \\
14 \\
131\end{array}$ & $\begin{array}{l}56 \% \\
16 \% \\
22 \% \\
29 \% \\
36 \% \\
52 \% \\
27 \%\end{array}$ & $\begin{array}{r}35 \\
60 \\
109 \\
47 \\
143 \\
45 \\
439\end{array}$ & $\begin{array}{l}3.50 \\
3.16 \\
3.21 \\
2.47 \\
4.09 \\
3.21 \\
3.35\end{array}$ \\
\hline $\begin{array}{l}\quad \text { ICST } \\
\text { CPS\&T } \\
\text { CCSE } \\
\text { OTHER } \\
\text { TOTAL I }\end{array}$ & $\begin{array}{r}r \\
640 \\
650 \\
600 \\
\text { ICST }\end{array}$ & $\begin{array}{r}46 \\
61 \\
7 \\
114\end{array}$ & $\begin{array}{r}16 \\
19 \\
2 \\
37\end{array}$ & $\begin{array}{l}35 \% \\
31 \% \\
29 \% \\
32 \%\end{array}$ & $\begin{array}{r}35 \\
74 \\
8 \\
117\end{array}$ & $\begin{array}{l}2.19 \\
3.89 \\
4.00 \\
3.16\end{array}$ \\
\hline $\begin{array}{l}\text { NEL } \\
\text { CAM } \\
\text { CEEE } \\
\text { CME } \\
\text { CBT } \\
\text { CFR } \\
\text { CCE } \\
\text { OTHER } \\
\text { TOTAL }\end{array}$ & $\begin{array}{l}710 \\
720 \\
730 \\
740 \\
750 \\
770 \\
700 \\
\text { NEL }\end{array}$ & $\begin{array}{r}94 \\
184 \\
132 \\
100 \\
63 \\
100 \\
17 \\
690\end{array}$ & $\begin{array}{r}11 \\
46 \\
24 \\
51 \\
23 \\
14 \\
6 \\
175\end{array}$ & $\begin{array}{l}12 \% \\
25 \% \\
18 \% \\
51 \% \\
37 \% \\
14 \% \\
35 \% \\
25 \%\end{array}$ & $\begin{array}{r}21 \\
105 \\
67 \\
188 \\
118 \\
38 \\
10 \\
547\end{array}$ & $\begin{array}{l}1.91 \\
2.28 \\
2.79 \\
3.69 \\
5.13 \\
2.71 \\
1.67 \\
3.13\end{array}$ \\
\hline $\begin{array}{l}\text { OTHER } \\
\text { OD } \\
\text { OPSP } \\
\text { OADPBE } \\
\text { ODA } \\
\text { TOTAL O }\end{array}$ & $\begin{array}{l}\text { R } \\
100 \\
120 \\
110 \\
300 \\
\text { OTHER }\end{array}$ & $\begin{array}{r}9 \\
27 \\
6 \\
63 \\
105\end{array}$ & $\begin{array}{r}1 \\
17 \\
1 \\
5 \\
24\end{array}$ & $\begin{array}{r}11 \% \\
63 \% \\
17 \% \\
8 \% \\
23 \%\end{array}$ & $\begin{array}{r}3 \\
63 \\
3 \\
6 \\
75\end{array}$ & $\begin{array}{l}3.00 \\
3.71 \\
3.00 \\
1.20 \\
3.13\end{array}$ \\
\hline TOTAL N & NBS & 1612 & 444 & $28 \%$ & 1434 & 3.23 \\
\hline
\end{tabular}

CMS - Cancer for Heceriele Sciace.

1MD - Inorganle Macariale O1vielon

PDD - Praccura Oad DePo
PD - Polyara Divialoa

IID - Raector Red10e100 D171010n

BEL - Kaclonel Englaeariag Leboracoty

CAM - Concer for Applied Hachadecleo

CMZ - Cencar for Manulaceuriag gaglacarios

CBz - Cancer for Building Iachoology

CPR - Concer for Plice Resarech

cCz - Cancer for Chascel Englacering

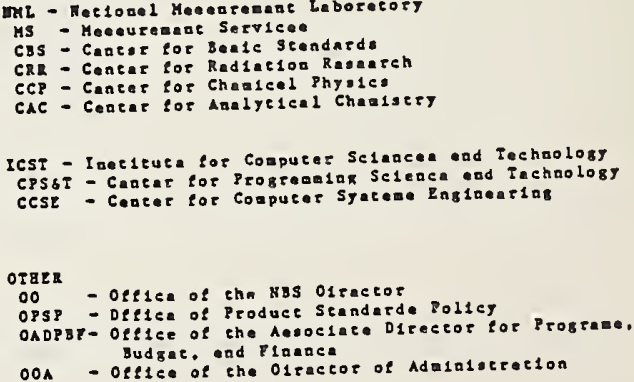

Meciodel hacentelacat haborecort

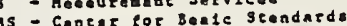

Cag - Cantar got Radiation Ragacish

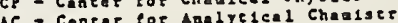

CST - Inetituta for Coapucar Sciancen end Technolozy CPSST - Cancar for Prograniar Sclerca oud Tachnol

Do - Optica of cha nBS O1tactor

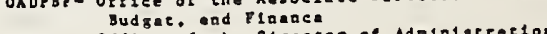


The following highlights technical and individual accomplishments for the year. They have been submitted by NBS center managers as representative of their various research areas and are limited to standards committee participation, but include highlights of significant contributions made by NBS staff to standards development in general.

\section{OFFICE OF THE DIRECTOR}

\section{Office of Product Standards Policy (OPSP)}

Dr. Stanley I. Warshaw served as head of the U.S. delegations to the 8 th meeting of the International Laboratory Accreditation Conference, the 8th meeting of the UNECE Government Officials Responsible for Standardization Policies, and the 7th International Organization of Legal Metrology Conference. Dr. Warshaw was also selected as a member of an international team by the International Organization for Standardization to give a series of lectures in China on standardization and laboratory accreditation. All of these activities have in common the development of guidelines and criteria that allow for the mutual acceptance of test data between nations, an area of growing importance to international trade.

Dr. Warshaw served as Chairman of the Interagency Committee on Standards Policy, which assists Government agencies in the implementation of OMB Circular A-119. The Committee effected the publication of two Federal guidelines, one covering agency use of private sector, third party certification and self-certification programs, and one covering guidelines for Government employees and agents participation in international treaty and non-treaty standards bodies.

John L. Donaldson was appointed Chairman of the Management Board for the International Organization for Standardization's Information Network (ISONET) from 1985 to 1987. The Management Board consists of nine standards information experts chosen from the membership of The Information Committee. The chairman directs programs to implement information policies of ISO regarding operation of ISONET (information centers in 56 countries and ISO), which provide information services related to standards, technical regulations, certification, and other standards related activities.

Walter G. Leight participated on a special subcommittee (on the International Use of ASTM standards) of the ASTM Board of Directors' Commit tee on the Voluntary Standards System (COVOSS). The subcommittee concluded that ASTM standards are widely used, helping to meet the needs for standards in 
international trade. Study results were summarized in the May and June 1984 issues of ASTM's Standardization News.

$\mathrm{Mr}$. Leight also participated in an international symposium in Brasilia concerning the implementation of the GATT Agreement on Technical Barriers to Trade (the "Standards Code"). He and a representative of the Office of the U.S. Trade Representative detailed the functioning of U.S. activities in support of the Standards Code. Delegates from Canada, France, Germany, and Japan and the GATT Secretariat in Geneva also made presentations.

The Standards Management Program of OPSP manages U.S. participation in the International Organization of Legal Metrology (OIML), a treaty organization that develops "International Recommendations" impacting wor ld trade of measuring instruments and which in 1984 affected about $\$ 6$ billion of U.S. exports. In October, the 49 OIML member nations approved 20 additional International Recommendations, five of which were developed by the United States with the support of NBS. During the year, NBS also supported U.S. efforts in the following areas:

- Cryogenic Meters--NBS in cooperation with a U.S. National Working Group consisting of State weights and measures officials, gas producers, and meter manufacturers developed a proposed International Recommendation for cryogenic meters based on requirements of NBS Handbook 44 and the European Industrial Gases Committee Code of Practice. The draft will be the subject of discussions in April 1985 when the OIML International Working Group is expected to meet in Paris.

- Electronic Weighing Instruments--Work on a draft OIML Recommendation on electronic weighing instruments continued in 1984. A U.S. National Working Group of scale manufacturers and OPSP staff produced a fourth draft Recommendation that was circulated to OIML member nations and was the subject of an international meeting in June. A subsequent draft is to be developed and will be the subject of what is expected to be a final meeting fo the International Working Group in June 1985. The final Recommendation will establish the international requirements for electronic weighing instruments used in trade and, thus, will have a significant impact on U.S. manuf acturers.

- Pollution Monitoring Instrumentation--NBS in cooperation with the EPA established broad based U.S. working groups which developed two preliminary draft International Recommendations on "Gas Chromatographs" and "Gas Chromatographs/Mass Spectrometers" for the measurement of pesticides and toxic substances and water pollution, respectively. These draft Recommendations were discussed at international meetings in Paris in June 1984, at which six other nations, including the United States, ISO, and UNIDO sent delgates. 
Another meeting of the International Working Group is planned for Washington, D.C. in May 1985 to discuss new drafts of recommendations for the measuring instruments indicated, future work, and scopes of activities.

International Comparison of Hardness Scale--NBS, through representation by ASTM Committee E28 on "Mechanical Testing," participated on behalf of the United States in an international comparison of hardness scales that was carried out by Czechoslovakia. A report of the results of the first step of the intercomparison was completed in 1984. It included the results of measurements of the Rockwe $11 \mathrm{C}$ and Vickers HV 30 hardness scales. Future plans are being developed and include comparisons of indenters and several other hardness scales.

Vocabulary of Basic and General Terms in Metrology--The vocabulary of basic measurement terms was completed and published by the four sponsor organizations - BIPM, OIML, ISO and IEC. The vocabulary is an important step towards international uniformity of measurement terms and definitions. Copies may be obtained from the Standards Management Program Office of OPSP.

Weights--OPSP provided the secretariat for the consolidation of five existing International Recommendations on comercial and laboratory weights. A second draft will be circulated to member countries in March 1985.

Prepackaged Products--A draft OIML Recommendation prepared by the United States on the labeling of packaged consumer goods was completed in 1984. The draft, based largely on existing U.S. requirements, establishes uniform requirements for the labeling of packaged consumer goods (food and non-food) in international trade. Formal acceptance of the draft is now underway through the responsible International Working Group. Subsequently, the draft will be submitted to all members of OIML for concurrence and eventual adoption. OPSP provides secretariat support for this endeavor. 
CMS staff co-chaired the steering committee meeting of the Advanced Materials and Standards project. The project was launched by the Versailles meeting of the Heads of State of the West's industrial nations. The Committee added two new projects, one on ceramics and one on polymer alloys, to the existing ones on wear test methods and standards for surface chemical analysis. Projects in five other areas were proposed for consideration at the next meeting of the committee: welding, polymer composites, high-temperature materials, cryogenic materials, and bioengineering materials.

Dr. Leonard Mordf in was appointed the U.S. delegate to ISO TC 135 on nondestructive testing. At the same time, he serves as the chairman of the U.S. Technical Advisory Group (TAG) to ANSI for ISO TC 135. In one of his first actions on behalf of the TAG, Mordf in invited the Soviet secretariat of TC 135 to convene the next meetings of the technical committee and its subcommittee in the United States. The meetings are tentatively scheduled for the week of October 28, 1985, in Philadelphia, Pennsylvania.

Samuel Schneider received the ASTM Award of Merit for outstanding contributions to the advancement of the voluntary standardization system. His award was based on demonstrated meritorious service and dedicated leadership in developing standards for refractory (ceramic) materials.

Camden Hubbard and Judith Stalick completed evaluation methods and data base design for the JCPDS. The JCPDS have adopted the system designed, developed and tested at NBS in collaboration with JCPDS Research Associates. The system is currently being used by the JCPDS to entirely reevaluate the 44,000 entry Power Diffraction File as well as build a computer data base.

Dr. Frederick Brinckman and Mr. William Blair have been welcomed as NBS representatives to the Permanent International Committee for Research on the Preservation of Materials in the Marine Environment (COIPM). This is an International organization for the conduct of cooperative research. The research projects are carried out by working groups formed from member organizations. NBS will be participating in the evaluation of organnotin measurement methods and will provide organnotin containing research materials for analysis by COIPM members.

David Lashmore was appointed Chairman of ASTM Subcommittee B08.07.09 on conversion and anodic coatings on aluminum. A draft was prepared for subcommittee ballot on the recommended practice for preparation of anodic films on aluminum using sulfuric acid anodizing.

David Lashmore was the U.S. representative to a meeting of ISO TC 107 on Metallic and Other Non-Organic Coatings in Turin, Italy. A new ISO standard was proposed, which will make use of the new NBS micrometer used for SEM calibration. 
CMS staff developed a draft amendment to ASTM standard G40 on Terminology Relating to Erosion and Wear. A total of seven new terms were involved; three of the terms were developed to serve as Society-wide definitions in response to an activity of the Committee on Terminology to reduce the number of redundant definitions.

Participation continued in round-robin measurement activity concerning Inicroindentation (microhardness) standards. A statistical analysis of data from 14 laboratories was carried out at NBS and recommendations were made relating to operator bias in low load test applications.

Participation continued in round-robin measurements of pitting and crevice corrosion of 316 type stainless steel through ASTM Committee F4. Reference material specimens were provided by NBS to assist the measurement process.

ASTM Committee G2 on Erosion and Wear recognized Arthur Ruff with an Award of Appreciation for his term as Chairman, and a Certificate of Appreciation for his work on a solid particle erosion standard.

The M.O.S.E.S. Award of ASTM was presented to Anna Fraker at a recent Committee F4 on Medical and Surgical Materials and Devices meeting in Montreal, Canada.

Dr. James Early developed guidelines for comparing domestic and foreign materials specifications taken from standards issued by ASTM, DIN, and JIS. The results of this study have been published by ASTM in the Journal of Testing and Evaluation.

Dr. Early also prepared a chapter on recycling ferrous scrap, which was published in the book Recycling, Fuel and Resource Recovery: Economic and Environmental Factors. Included was a discussion of the role of standards on the development of scrap markets for ferrous scrap recovered from municipal solid waste. This chapter complements an earlier chapter written by Dr. Early and published in The Encyclopedia of Chemical Technology. 
The tenth annual meeting of the International Standards Organization Council Cominittee on Reference Materials (ISO-REMCO) was held at NBS, October 15-19, under the chairmanship of Mr. George Uriano. At this meeting the Committee devoted its work to five main topics:

1. Development of REMCO Guide 33 "Use of Reference Materials"

2. Development of REMCO Guide 35 "Certification of Reference Materials"

3. COMAR, a Computerized System for Indexing Reference Materials on a Worldwide Basis

4. Revision of the ISO Directory of Certified Reference Materials

5. Development of the future program of REMCO.

During the meeting a special symposium was held on the use of reference materials. The NBS speakers were Drs. John Taylor, John Mandel, Robert Paule, and Mary Croarkin.

On July 17, NASA and Lehigh University presented to NBS 15 grams of $10 \mathrm{um}$ polystyrene spheres produced aboard the NASA space shuttles. The material is now being certified by the Office of Standard Reference Materials in a joint measurement program with the American Society of Testing and Materials (ASTM) as a particle size standard reference material for dimensional metrology. The ASTM portion of the work is being led by Research Associate Dr. Russell Obbink, while measurements at NBS are being conducted by Drs. Thomas Lettiere, Theodore Vorburger, Arie Hartman, and Gary Hembree.

The Office of Standard Reference Materials is working with a special committee of ASTM (S-17) to define the future production program for metal reference materials. The committee is conducting a survey of about 500 companies as to their requirements for metal reference materials. The committee met in November in Williamsburg, Virginia, to discuss the results of the survey and the production program for the coming years.

Center for Radiation Research (CRR)

A draft standard procedure for "Benchmark Referencing of Surveillance Dosimetry for the Pressure Vesse ls of Light Water Reactors" was completed in 1984. This standard for the American Society for Testing and Materials is scheduled for ballot in January 1985. The standard is under the jurisdiction 
of the Nuclear Radiation Metrology (E10.05) Jurisdiction Subcommittee. Since 1977, NBS has been involved in an international program sponsored by the Materials Research Division of the Nuclear Regulatory Commission to assist in upgrading the neutron dosimetry performed commercially at nuclear power plants to monitor the radiation exposure responsible for the embrittlement of steel in reactor pressure vessels.

NBS has played a lead role in the benchmarking effort by establishing bases for quality assurance and providing irradiations of materials in known neutron fluences to establish the path for traceable standardization of neutron surveillance dosimetry. The development and maintenance of standard neutron fields at NBS has made this possible. The principal standard neutron fields are the Californium-252 spontaneous fission spectrum facilities in the Nuclear Radiation Division and both the Uranium-255 fission spectrum and the Intermediate-energy Standard Neutron Fields of the NBS Research Reactor.

Dr. Jack Hsia has been named Associate Director of Division 2 on "Physical Measurement of Light and Radiation" by the Council of International Commission on Illumination in Apri1. Dr. Hsia has responsibility over the technical activities of six committees in the following areas: measurement of gloss, luminescence intercomparison, international comparison transmittance measurements, gonioreflectory of standard material, survey of reference materials for testing the performance of spectrophotometers and colorimeters, and measurement of ref lectance and transmittance.

In July, nearly 160 registrants attended the Workshop on Radiation Survey Instruments and Calibrations held at NBS in Gaithersburg. The purpose of the workshop was to have open discussion of a possible testing program based on a national standard for the performance of radiation survey instruments, and the establishment of a national system of secondary standards laboratories. Sponsorship of the workshop was balanced among agencies and organizations in the private, state, and federal sectors, and the program was structured to present each of these three perspectives. Because the registrants also represented a wide range of concerns and interests, the workshop was highly successful. The interactions that began during the workshop will be continued in a national committee for which NBS will serve as the secretariat. This committee will be formed in the near future to plan and guide implementation of a national instrument testing program and the establishment of a system of secondary standards laboratories in the private sector.

Based largely on NBS Technical Note 1177, "Elements of Thermography for Nondestructive Testing," written by J. Cohen, a draft glossary for infrared thermography, has been prepared by ASTM Section E7.10.04 on Infrared Methods of Nondestructive Testing Technical Note 1177 presents an elementary review of thermal imaging systems, with emphas is on the application of thermography to nondestructive testing. The paper is intended to be readable to scientists and program managers without previous background in thermography or infrared technology. 
William L. McLaughlin received a special award for excellence in technology transfer in May from the Federal Laboratory Consortium for Technology

Transfer. This award was given to Mr. McLaughlin for developing and bringing to the marketplace an accurate, inexpensive, broad range fibre-optic radiation dosimeter to assure product reliability for the radiation processing industry. It is expected that the extensive use of these dosimeters will lead to the standardization of radiation measuring systems for the radiation processing industry.

Two argon arcs, designed and calibrated in the Atomic and Plasma Radiation Divison, have been used to calibrate the faint object spectrograph (FOS), one of the instruments due to fly on the space telescope. This spectral irradiance calibration in the near and vacuum ultraviolet was effected using a standard maxi-arc and a standard mini-arc (NBS Standards $7.6 \mathrm{~A}$ and B) to calibrate the space telescope optical simulator (STOS). Utilizing five lamps, the STOS provides optical emissions that simulate expected observations by the orbiting space telescope. The individuals responsible for the Jevelopment of the arc standards are W. R. Ott and J. M. Bridges, and the calibration of the STOS was carried out by J. Z. Klose over the period from March through october in consultation with the lead contractor, Martin Marietta Denver Aerospace.

A vacuum ultraviolet spectroradiometer recently developed in the Center for Radiation Research has been used to select and calibrate a deuterium lamp to be flown on the Solar Ultraviolet Spectral Irradiance Monitor (SUSIM) space shuttle experiment as an in-flight radiation standard. This experiment is the first to utilize a calibrated source in space. The spectroradiometer is unique in that it was designed to be completely oil-free to simulate the environment of outer space, and its range for irradiance calibrations extendends down to $115 \mathrm{~nm}$ in the vacuum ultraviolet. The selection and calibration of the flight lamp was carried out by J. Z. Klose using NBS argon mini-arc near and vacuum ultraviolet radiometric standards $7.6 \mathrm{~A}$ and $\mathrm{B}$. This work was completed in February at which time the flight lamp was delivered to the Naval Research Laboratory for incorporation into the SUSIM.

The FASTBUS modular high speed data acquisition and control system for high energy physics and other applications is an interlaboratory development coordinated and managed by Louis Costrell of the NBS Center for Radiation Research. The basic specification has been approved as a standard of the Institute of Electrical and Electronics Engineers and also of the American National Standards Institute with the designation ANSI/IEEE Standard 9601984. This standard is being used in the major high energy physics laboratories in the United States and abroad and by numerous manufacturers of nuclear instrumentation. Louis Costrell, who also serves as Technical Advisor to the U.S. National Committee of the International Electrotechnical Commission (IEC) and as Chief U.S. Delegate to the IEC Committee on Nuclear Instruments, has initiated the processing of the FASTBUS specification as an international standard of the IEC. 
The first state-operated facility for calibration of radiation measuring instruments was opened formally in June, in Springfield, Illinois. Those who participated in the dedication ceremony included the Deputy Director of NBS, a representative of the Office of the Governor, the Executive Secretary of the Conference of Radiation Control Program Directors (CRCPD), and officials of the Illinois Department of Nuclear Safety. Initially, the center will use $X$-rays and gamma rays to calibrate instruments used for measurements in support of medical diagnostics and radiation protection. During the opening ceremony, the laboratory was granted accreditation by the CRCPD to operate in accordance with specific criteria developed by its Radiation Measurements Committee. Similar laboratories are under development in South Carolina, Washington, California, and Arkansas. These state-operated facilities are now being developed with guidance and technical support from NBS.

CRR has hosted ANSI N42.2, Subcommittee on Calibration Procedure Standards, over recent years at approximately six month intervals. A standard entitled "American National Standard Specifications for Sealed Radioactive Check Sources Used in Liquid-Scintillation Counters" is nearing final approval. A five-year review of the standard entitled "Calibration and Usage of 'Dose Calibrator' Ionization Chambers for the Assay of Radionuclides" has essentially been completed.

CRR has provided radioactive materials to Pacific Northwest Laboratories under the sponsorship of the Department of Energy and Nuclear Regulatory Commission. These materials have been used for round-robin intercomparisons with Health Physics Laboratories engaged in the determination of radioactive hazard to occupationally exposed individuals. A standard (ANSI N 13.30, "Performance Criteria for Radiobioassay", presently in draft stage) will be based, in part, on the results of the intercomparison.

Allan D. Carlson serves as Chairman of the Standards Subcommittee of the Cross Section Evaluation Working Group of the National Nuclear Data Center. Significant progress has been made on the evaluation of the "neutron standards" for version 6 of the national evaluated nuclear data file known as ENDF/B-VI.

NBS has been playing a key role on the neutron group of ISO/TC 85/SC $2 /$ GT 2 Reference Radiation working group of the Radiation Protection Subcommittee of the Nuclear Power technical committee. A new standard, "Neutron Reference Radiations for Calibrating Neutron Measuring Devices Used for Radiation Protection and for Determining their Response as a Function of Neutron Energy" (ISO/DP 8259) has been sent to the ISO Central Secretariat in Geneva for the final voting procedure. It is anticipated that the standard will be adopted by ISO. Several of the reference radiations incorporated in the standard were developed at NBS.

The neutron group of ISO/TC85/SC2/GT2 is now working on a second standard, essentially devoted to the proper use of the reference radiations specified in the first standard. This document, "Procedures for Calibrating and 
Determining the Energy Response of Neutron Measuring Devices Used for Radiation Protection", is still in draft form. It relies heavily on specific procedures developed at NBS. More important, however, the whole point of view of the document with regard to such matters as correcting for scattering effects is largely due to NBS input, which has stimulated other workers to pick up our ideas and extend them further.

Current research in the Center for Radiation Research will form the basis for an extension to photon energies between 4 and 9 MeV of ISO 4037-1979, "X and Gamma Reference Radiations for Calibrating Dosimeters and Dose Ratemeters and for Determining Their Response as a Function of Photon Energy."

An Addendum to ISO 4037-1979 covering the description of several methods for producing 4- to 9-MeV photon beams suited for the calibration of radiation-protection instruments, including the method under study at NBS, has been prepared by a working group of ISO TC85/2/2. The current draft of this Addendum has been circulated to all members of ISO TC85/2/2. A further Addendum, covering the characterization of these photon beams by spectrometry and dosimetry, is under preparation by M. Ehrlich. The second draft of this Addendum was submitted to the working group in June.

\section{Center for Chemical Physics (CCP)}

The Versailles Project on Advance Materials and Standards (VAMAS) has considered the establishment of Technical Working parties in specific materials areas. A proposal for a Surface Chemical Analysis Working Party was prepared by Dr. M.P. Seah of the UK National Physical Laboratory and Dr. C.J. Powell of NBS and approved by the VAMAS Steering Committee in June, 1984. The proposal described the growth and diversity of surface analysis in the development of advanced materials in modern technologies and, additionally, the use of surface analysis for improved films and coatings. The principal techniques of surface analysis in common use were identified and the technical limitations to accurate surface analyses summarized. Accurate surface analyses require:

1. knowledge of the principles of the measurement method,

2. knowledge of the behavior of the measuring instrument, and

3. correct interpretation and expression of the final measured result.

Standards for the measurement of surface composition with known accuracy and for the reliable determination of chemical state will thus require:

1. a base of principles, definitions of terms, and suitable equations,

2. reference procedures for the measurement of intensities and spectral features, 
3. procedures and data for instrument calibratons,

4. reference data for material parameters such as elemen-

tal sensitivity factors, matrix terms, chemical state

spectra, ion sputtering rates, etc., and

5. standards for specifying an analysis.

Specific needs were identified for the common methods of surface analysis, Auger-electron spectroscopy, X-ray photoelectron spectroscopy, and secondary ion mass spectrometry together with the needs for ion sputtering which is used to obtain composition versus depth information in films and coatings. Existing standards activities in the member countries were reviewed and suggestions were made for additional standards for surface chemical analysis by scientists in the member states of VAMAS.

Center for Analytical Chemistry (CAC)

The International Ozone Commission, at its Quadrennial Ozone Symposium held in Halkikiki, Greece in September, recommended to the World Meterological Organization the adoption of new NBS measurements of the ultraviolet absorption cross-section as the reference data set for processing atmospheric ozone observations. This recommendation is based on the research of Dr. Arnold Bass, recently completed, which included a detailed investigation of the temperature dependence resulting in the most accurate evaluation of the absorption cross-section of ozone. These data are required for measurement of the ozone distribution in the earth's atmosphere as determined by observation of transmittance of ultra-violet solar radiation using earth stations and satellite-born instruments. The new reference data are expected to provide an eight-fold increase in the accuracy of these important measurements.

In a cooperative effort between NBS, the Commission of the European Communities, and the U.S. Department of Energy, B. Stephen Carpenter and Robert Greenberg have developed a new Standard Reference Material (SRM 969) for non-destructive determination of the $235 \mathrm{~J}$ Abundance in nuclear materia1s. The issuance of this SRM is expected to substantially improve, on an international scale, accountability measurements in the nuclear industry.

Dr. John K. Taylor was granted the ASTM Award of Merit and the honorary title of Fellow of the ASTM in April 1984. The award was given "for his exceptional contributions in the area of quality, calibration, and precision related to development of standard test methods of Committee D22 on Sampling and Analysis of Atmospheres." Dr. Taylor is an active member of four ASTM Committees and is presently Chairman of committee 022.

Dr. Harry S. Hertz has been chosen as President-elect of the National Committee for Clinical Laboratory Standards (NCCLS). The NCCLS, representing 
the major professional, governmental, and industrial organizations interested in this field, develops methodologic standards and guidelines and specifications for reference materials for use in clinical analysis. Dr. Hertz has served previously as Secretary of the NCCLS and as a member of its Board of Directors.

Mr. John A. Norris received the ASTM Award of Merit "for outstanding efforts in Committee E2 on Emission Spectroscopy as Recording Secretary and subcommittee chairman and for his help in sharing spectro-chemical techniques and statistical analysis concepts of NBS with ASTM."

Dr. Harry L. Rook has been appointed as Chairman, ASTM D22.03, Subcommittee on Ambient Air Measurements in July. Dr. Rook also served as Co-Chairman of Committee D22's Symposium on Measurement of Hazardous Waste, held at Johnson College in Vermont. 
In 1984 the Institute for Computer Sciences and Technology completed development of the following Federal Information Processing Standards (FIPS):

FIPS PUB 8-5 Metropolitan Statistical Areas Including CMSAs, PMSAs, and NECMAS

FIPS PUB 10-3 Countries, Dependencies, Areas of Special Sovereignty, and Their Principal Administrative Divisions; Revisions to FIPS PUB 10-2

FIPS PUB 103 Codes for the Identification of Hydrologic Units in the United States and the Caribbean Out lying Areas

FIPS PUB 105 Guideline for Software Documentation Management

FIPS PUB 106 Guideline on Software Maintenance

FIPS PUB $107 \quad$ Local Area Networks: Baseband Carrier Sense Multiple Access with Collision Detection Access Method and Physical Layer Specifications and Link Layer Protoco1; adopts IEEE 802.2 and 802.3

FIPS PUB 108 Alphanumeric Computer Output Microform Quality Test Slide; adopts AIIM MS 28-1983

The following standards-related publications were issued in 1984:

NBS Spec. Pub. 500-105 Guide to Software Coversion Management

NBS Spec. Pub. 500-106 Guide on Software Maintenance

NBS Spec. Pub. 500-108 Guide on Data Models in the Selection and Use of Database Management Systems

NBS Spec. Pub. 500-111 Standardization Issues for Optical Digital Data Disk (OD3) Technology

NBS Spec. Pub. 500-115 Report on Approaches to Database Translation

NBS Spec. Pub. 500-117 Selection and Use of General Purpose Programing Languages

NBSGCR $84-462$

Physical Database Processor Preliminary Specifications

NBSGCR $84-461$

Logical Database Processor Interface Specifications 
Center for Programming Science and Technology (CPS\&T)

Leonard Gallagher contributed to the development of proposed standards for Database Language NDL and Database Language SQL by ANSI technical committee $X 3 \mathrm{H} 2$, Database. He prepared the tutorial documents associated with these proposed standards and serves as the X3H2 International Representative. James Upperman chairs ANSI technical committee X3L5, Labels and File Structure, which is working with ISO/TC97/SC15 to develop a Data Descriptive File Standard.

David Jefferson and Elizabeth Fong, co-chairs of the Database Architecture Framework Task Group (DAFTG) of the ANSI/X3/SPARC Database System Study Group (DBSSG), were major contributors to a draft report entitled "Reference Mode 1 for DBMS Standardization." The reference model is a proposed planning document to guide the future development of database system standards by $\times 3$ committees.

NBS research in database languages and data interchange forms has provided technical support to ANSI and ISO committees developing standards in these areas. NBS Spec. Pub. 500-108, Guide on Data Models in the Selection and Use of Database Management Systems, shows how newly proposed American National Standard database languages for network and relational database management systems might be applied in practice. NBS Spec. Pub. 500-115, Report on Approaches to Database Translation, describes how standard database structures might be represented for database interchange using the recently adopted ISO Data Descriptive File standard, ISO 8211.

In June Leonard Gallagher was appointed to convene the ANSI/X3/SPARC Data Interchange Study Group which wi1l examine data interchange requirements for $\times 3$ projects dealing with programming languages, office systems, open systems interconnection, data representation, graphics, data dictionary, and database. The objective of the study is to identify those elementary data types most important for data interchange among different systems and to determine the feasibility of alternative data representation formats. This work is expected to advance $\times 3^{\prime} \mathrm{s}$ planning for future data interchange standards.

In September, the IEEE Computer Society's Software Engineering Standard Subcommittee (SESS) working group P1042 completed its first draft of a Guide for a Software Configuration Management Plan. Wilma Osborne contributed to the development of the draft by preparing a section on audits and reviews.

Patricia Powell and Roger Martin contributed to the development of a draft Standard for Software Reliability Measurement by the IEEE Computer Society's Software Engineering Standards Subcommittee (SESS) working group P982. 
A meeting of the IEEE Computer Society's Software Engineering Standards Subcommittee (SESS) working group to develop Software Maintenance Standards was held in November at NBS.

Helen M. Wood has been appointed to the IEEE Computer Society's Standards Board.

Allen L. Hankinson has been appointed to IEEE Computer Society's Standards Coordinating Committee. He also serves as the IEEE Computer Society representative to the International Standards Coordinating Committee.

Albrecht J. Neumann has been appointed the International Representative of ANSI Committee X3K1, Project Documentation.

Center for Computer Systems Engineering (CCSE)

At the request of ANSI technical committee $\times 3 B 5$, Digital Magnetic Tape, ICST will develop a new Standard Reference Material, Secondary Signal Amplitude Reference Magnetic Tape Cartridge 6400-10000 ftpi. These cartridges are used worldwide principally in applications for backup of fixed Winchester disks.

ANSI technical committee $X 3 L 2$, Codes and Character Sets, approved ICST'S proposal to develop a Quantitative Verification System for the North American Presentation Level Protocol Syntax (NAPLPS). The verification system will result in a standard set of NAPLPS text frames to be made available to users, manufacturers and service providers of videotex and teletext equipment.

Dana Grubb co-authored a report published by the National Telecommunications and Information Administration. Entitled American National Standard X3.102 User Reference Manual, the report discusses ANSI X3.102, "Data Communication Systems and Service: User-Oriented Performance Parameters," covers the approach and content of the ANSI standard, and examines the meaning and importance of each standard parameter.

In July emerging ISO standards for networks were demonstrated at the National Computer Conference, resulting from a cooperative effort by ICST, General Motors Corp., Boeing Computer Services, and 13 computer manufacturers and communication companies. The standards demonstrated were IEEE 802.2 type 1 class 1 Logical Link Control; IEEE 802.3 Carrier Sense Multiple Access with 
Collision Detection (CSMA/CD); IEEE 802.4 Token Bus; the ISO Class 4 Transport Protocol; and an extended subset of the ISO File Transfer Protocol. These standards are being processed as draft proposals or as draft international standards by ISO.

This demonstration of two local area networks was a first step toward making computer-to-computer communications feasible using international standards. These international standards will give network users flexibility and options to build networks for future information processing needs.

ICST developed the test methods that supported the development and implementation of the standards and enabled the companies participating in the demonstration to assure that their products would work together in an operating environment.

In August, ICST initiated a workshop series for implementors of ISO's Open Systems Interconnection (ISO) Reference Model. Participating in the workshops are representatives of more than 40 companies that develop computer and communications systems. The workshops will consider several demonstration projects including implementation of ISO draft and proposed network protocol standards in electronic message, manufacturing automation, and public data network applications.

ICST assisted the Department of the Treasury in developing a new policy to assure the integrity of its electronic funds transfer (EFT) data. A directive issued by the Treasury requires the use of American National Standard (ANSI) X9.9, Financial Institution Message Authentication, or an equivalent method approved by the Treasury. ICST was a major contributor to the X9.9 standard, and to other voluntary standards developed for the banking community. ICST will continue to assist the Treasury in the implementation of the standard by developing methods for verifying the correct performance and assuring the reliability of equipment and techniques for protecting EFT data.

In October, ICST participated in a government/industry news conference to announce support for the proposed Intelligent Peripheral Interface (IPI) Standard being developed by ANSI comnittee X3T9.3, Device Level Interface. The IPI is a high performance interface that provides for physical level connection of peripherals such as disks, tapes, printers, and terminals to a wide range of computers from small systems to large mainframes. More than 40 companies also announced their support for the IPI standard, which is expected to serve industry needs for the next 10 to 20 years.

John Little was elected Vice Chairman of ANSI task group X3L2.3, Two Byte Character Set. 
NATIONAL ENGINEERING LABORATORY

Law Enforcement Standards Laboratory (LESL)

In 1984, the Law Enforcement Standards Laboratory completed the development of the following performance standards that will be issued by the National Institute of Justice (NIJ) as voluntary national standards as part of its Technology Assessment Program:

- NIJ Standard-0112.00, "9 mm/45 Caliber Autoloading Pistols"

- NIJ Standard-0224.00, "Personal/Mobile FM Transceivers"

- NIJ Standard-0502.00, "Flashing Warning Light Systems for Law Enforcement, Emergency and Service Vehicles"

o NIJ Standard-0210.00, "Mobile FM Transceivers"

In addition, LESL completed the revisions of two previously-issued NIJ standards, to ref lect changes in the state-of-the-art of commercial products:

- NIJ Standard-0101.02, "Ballistic Resistance of Police Body Armor"

- NIJ Standard-0108.01, "Ballistic Resistant Protective Materials"

The National Institute of Justice published four voluntary national standards that were developed by LESL:

- NIJ Standard-0105.01, "Crash Helmets"

- NIJ Standard-0222.00, "Surveillance Receiver/Recorders"

- NIJ Standard-0321.00, "Control Units for Intrusion Alarm Systems"

- NIJ Standard-0606.00, "Portable Organic Vapor Detectors"

LESL also continued to provide support to the National Highway Traffic Safety Administration (NHTSA) in the implementation of the NHTSA model specification for speed measuring radar devices.

Center for Applied Mathematics (CAM)

NBS co-sponsored a 5-day international conference on fatigue science in october at Dallas, Texas. The purpose of the conference was to promote a 
rational approach in developing more accurate computer-assisted testing standards for determining the fatigue and fracture resistance of metals, plastics, composites, and building materials. More than 200 participants from 16 countries attended. The American Society for Testing and Materials (ASTM) through Committee E-9 on Fatigue and Committee E-24 on Fracture was the principal co-sponsor. Several NBS people presented talks at the conference. Jeffrey Fong and Richard Fields served as chairman and secretary, respectively, of the organizing committee.

NBS provided assistance and research support for an on-site tally of standards-related ballot and instant analysis of voting results using a personal computer (PC) and state-of-the-art analysis and database software. Jeffrey Fong and Robert Cramer (711) contributed a PC-based, analysis and database integrated software to the evaluation of 43 items of fatigue-testing-standards-related questions by up to 120 researchers from 16 countries. During the 5-day conference, more than 10,000 integers from the ballots were loaded to the PC in five batches and analyzed on-site to permit a presentation of the tally and analysis results two hours after the last vote was collected.

The result of this first attempt was documented in a committee report. The title of the report is "An Application of DATAX to the Analysis of an ASTM Symposium Ballot," (Nov. 16, 1984).

CAM staff has provided technical support for the development of economic analysis methods and guidelines for use by voluntary standards organizations. The support was provided through participation in ASTM and the International Council for Building Research (CIB). The Building Economics Subcomittee of ASTM E-06-81, chaired by Harold Marshall, has three standards in ASTM review. They are "Recommended Practice for Measuring Net Benef its for Investments in Buildings and Building Systems," "Standard Practice for Measuring Simple and Discounted Payback for Investments in Buildings and Building Systems," and "Standard Practice for Measuring Internal Rates of Return for Investments in Buildings and Building Systems." All are based on NBS technical reports.

ASTM distributed a "Building Life-Cycle Cost" Computer Program on a diskette along with its documentation as an adjunct to the building economics standards. This program/documentation package was developed at NBS.

James Lechner has been active on Special Commitee 150 of the Radio Technical Commission for Aeronautics. The Committee is charged with developing standards that will allow safe operation of aircraft at reduced vertical separation above 29,000 feet altitude.

Dr. Lechner has been active both in the main Committee deliberations and in the Working Groups and has consulted with statisticians from the FAA Technical Center. He has written several discussion papers, participated in 
drafting the interim report issued in November; and presented a paper at the Statistics Symposium on National Energy Issues describing the risk-analys is context and some of the statistical concerns of this problem.

The Radio Technical Commission for Aeronautics is a joint government-industry group that mingles staff from the FAA, the International Air Transport Association, federal military agencies with air traffic control responsibility, civil airlines representatives, and technical representatives from the producers of avionic instrumentation.

ISO Guide 35, "Certification of Reference Materials - General and Statistical Principles," which is based heavily on NBS contributions, was approved by the ISO/REMCO Committee (The Council Committee on Reference Materials of The International Organization for Standardization) in June. Keith Eberhardt wrote one section of the document and served as technical editor for the statistical material it contains. Another section of the Guide was based on material taken from chapter 3 of the "Role of Standard Reference Materials in Measurement Systems", by J.P. Cali, et al., NBS Monograph 148 (1975), which was written by Harry Ku. George Uriano, of the NBS Office of Measurement Services and Chairman of REMCO, served as general editor of the Guide.

Mary Natre 1la received the ASTM Award of Merit at the April meeting of ASTM Committee E-11. She was cited for outstanding, intelligent, and productive leadership in the development of standards and applied statistical publications produced by Committee E-11, especially as Chairman of Subcommittee E11.03 on Statistical Analysis and Control Techniques.

\section{Center for Electronics and Electrical Engineering (CEEE)}

A new ANSI standard, C12.13, and the revision of an existing ANSI standard C12.4, have been approved for publication. These standards were developed by the Electricity Metering Committee which has the IEEE for its secretariat and which is chaired by Raymond Turgel of CEEE. To provide an incentive for consumers to use electric generating capacity more efficiently, several utilities now bill their customers on a multiple tariff basis using so-called time-of-use electricity meters. The C12.13 standard provides for a read-out format that makes the task of reading such meters and recording the data easier and more uniform throughout the industry.

The final draft of an International Electrotechnical Commission (IEC) standard for the measurement of power frequency electric fields was recently prepared by Martin Misakian. The draft is based, in part, on the results of NBS' investigation into the measurement of $60-\mathrm{Hz}$ electric fields. As Secretary (Chairman) of IEC Technical Committee 42 Working Group 6, Dr. Misakian oversaw the preparation of four revisions of the draft which were 
reviewed by members representing England, the Soviet Union, France, China, Germany, Belgium, Canada, Egypt, Italy, and Sweden. The draft has been circulated by the IEC Central office to the national committees represented in Technical Committee 42 (TC42) for comments and will be considered in detail by TC 42 at the IEC general meeting in May 1985 in Montreal.

Workers in CEEE are in the midst of a round robin, which is intended to circumscribe and quantify the problems with power meters being used in the fiber optics industry. Preliminary work indicates that the discrepancy between meters may be as much as 40 percent. The round robin was developed as a result of that discrepancy. It is being conducted in cooperation with the Electronics Industries Association (EIA) P-6 Committee on Fiber Optics. It is expected that the experiment will not be completed before early 1985 .

CEEE staff have published NBSIR-83-1691 which is intended for users, vendors, and metrologists who have a need to measure the attenuation of telecommunication-grade multimode fibers. The document is entitled "Measurement of Multimode Optical Fiber Attenuation: An NBS Special Test Service." The technique that is described is the one recommended by the Electronics Industries Association (EIA). The technique was developed in the EIA P-6 Committee on Fiber Optics. The document brings together the essence of two EIA recommended Fiber Optic Test Procedures (FOTPS), as published in the Recommended Standard RS 455: FOTP 50, dealing with light launch conditions for fiber attenuation measurements, and FOTP 46 , dealing with the measurment techniques.

The SEMI (Semiconductor Equipment and Materials Institute) Ceramic Packages Thermal Measurements Task Force, chaired by Frank Oettinger, is concerned with the standardization of techniques to thermally characterize ceramic packages. Due to the inherent difficulties in analyzing and measuring the thermal properties of active integrated circuit chips, an approach using specifically designed thermal test chips for evaluating packaging schemes was proposed by NBS. A computer program to analyze the temperature distribution of packaged thermal test chips has been fully documented by John Albers and made available to the industry. In addition, a review article on the design and utitlization of thermal test chips has been written by Frank Oettinger and published in the February issue of Solid State Technology. With these two publications as background, two documents entitled "Specification for Referee Thermal Test Chip" and "Test Method for Thermal Measurements for Ceramic Packages" have been written by Mr. Oettinger and circulated to the SEMI Ceramic Packages Subcommittee for comments.

Staff members of CEEE are editing a major publication of the Electronic Industries Association titled "MOSFETs". The publication, originated in EIA Committee $\mathrm{JC}-25$, Committee on Power Transistors, is a handbook intended to guide power MOSFET (Metal Oxide Semiconductor Field Effect Transistor) users in understanding the characteristics and specifications of these devices. A chapter on thermal characteristics was taken directly from a publication of 
NBS research. NBS will also coordinate and participate in a round-robin measurement exercise to establish the capabilities of industrial laboratories in making thermal measurements on power MOSFETs. Sixteen power semiconductor device manufacturers and users are represented on the committee.

An alternative approach for determining the interlaboratory precision of a test method was proposed to the ASTM Subcommittee F-1.11 on Quality and Hardness Assurance by Harry Schafft in collaboration with John Mandel of NML. The alternative approach involves parallel rather than serial handling. The approach is particularly appropriate in the case of a test method that involves measurements that tend to degrade the device.

The approach was tested in a determination of the interlaboratory precision of a newly modified Standard Method for Measuring MOSFET Linear Threshold Voltage. All measurements by the eight participating laboratories (including the one at NBS) were completed in about four months with no device failure. By way of contrast, the interlaboratory experiment used for an earlier version of the test method took over two years to complete and resulted in the failure of over one third of the test devices at some time during the experiment.

A new ASTM test method on the "Determination of the Interstial 0xygen Content of Silicon Slices by Computer-Ass isted Spectrophotometry" has been accepted for publication in the gray pages of the 1984 Annual Book of ASTM Standards. This test method was developed by a task force appointed by ASTM Subcomitee F1.04 on the Physical Properties of Semiconductors. Aslan Baghdadi is Chairman of the task force. The other members of the task force include representatives both from the instrument manufacturers (Perkin-Elmer, IBM, Digilab, Nicolet) and the users (Bell Labs, Texas Instruments, WackerSiltronic).

James Ehrstein was a co-recipient of the Elmer Thurber Award of ASTM Committee F-1 in October. The award was presented for significant publication in the area of semiconductor electronics standardization.

Stanley Ruthberg has drafted a new standard for the hermetic testing of electron devices. The standard was approved by ASTM Committee F-1 on Electronics in the spring. It is entitled "Standard Test Method for Package Attenuation Coefficient of a Sealed Device for Radioisotope Hermetic Test" and is numbered ASTM F866. This is the last of a series of three such standards drafted by Mr. Ruthberg.

A complete revision of ASTM Standard F98, "Standard Recommended Practice for Determining Hermiticity of Electron Devices by a Bubble Test", was drafted by Stanley Ruthberg for ASTM Committee F-1.09 on Enclosures, Substrates, and Films. It was approved by Committee F-1 of ASTM in October. 
An extensive revision of ASTM Standard F76 "Method for Measuring Hall Mobility and Hall Coefficient in Extrinsic Semiconductor Single Crystals" has been undertaken by staff members of CEEE. This method is used for measuring the resistivity and Hall coefficient and for determining the Hall mobility in extrinsic semiconductor single crystals. The revision was initiated by ASTM Subcommittee F01.15 on Gallium Arsenide to extend the original method to accomodate semi-insulating semiconductors such as gallium arsenide and indium phosphide. Alan Seabaugh and Michael Bell of the CEEE staff are coordinating the effort, which has a participation of 47 people: 35 industrial laboratories, 3 government laboratories, and 2 universities.

A revised draft of the document "Standard Practice for Characterizing Semiconductor Deep Levels by Transient Capacitance Techniques" was prepared by Robert Thurber and Jeremiah Lowney. This standard practice is being developed by Subcommittee 6 on Electrical and Optical Measurements of ASTM Committee F-1 on Electronics. In an effort to reach a wider and more knowledgeable audience, the draft was sent for comments to 16 individuals outside of ASTM who are active in deep level measurements.

The first superconducting critical standard reference material (SRM 1457) was certified in June. The SRM was created for calibrating apparatus used to measure this key parameter of superconductor products, critical current, and will be useful to buyers and sellers of superconductors and researchers in superconductor technology. The SRM me asurement technique is the ASTM Standard Test Method B714-82. The SRM will also serve as a means for interlaboratory comparison that will further advance the consensus and evolution of the standard test method.

\section{Center for Manufacturing Engineering (CME)}

Robert Hocken and Thomas Carlton have completed final revisions to ASME Proposed Standard B89.1.12 on Performance Evaluation of Coordinate Measuring Machines after a full year of trial use by the manufacturing community. This new standard focuses on meeting the needs of commerce by providing straightforward methods to establish performance specifications and to test threedimensional coordinate measuring machines, satisfying the needs of both manufacturers and users of this equipment. The standard breaks new ground in two significant areas and views performance testing with a system perspective. First, the interaction of the measurement environment and machine performance is directly addressed by providing functional tests to assess this influence. Second, although a measuring machine is a complex electromechanical device with many error sources, the emphasis in testing is placed on functional performance of the entire system in its normal method of use rather than on performance of individual elements of the machine. This 
general approach has gained wide acceptance here and abroad over the course of the one-year trial period. NBS also now supplies a Socketed Ball Bar Set (Standard Reference Material \#2083) in support of the test methods specified in the new Standard.

Eleven vendors of CAD/CAM equipment joined the National Bureau of Standards in a working demonstration of the transfer of CAD/CAM part files using the Initial Graphics Exchange Specification (IGES). The demonstration took place during the AUTOFACT 6 conference and exhibition in October at the Anaheim Convention Center, Anaheim, CA.

The objective for the IGES demonstration was to show the breadth and depth of vendor implementations by way of an intersystem data exchange of a complicated mechanical test part.

Applicon, CADLINC, Computervision, Control Data, Graftek, Hew lett-Packard, IBM, InterCAD, Matra Datavision, MCS Inc., and SDRC demonstrated the IGES capabilities of their systems. Four of these vendors--CADLINC, HewlettPackard, InterCAD, and SDRC--made their debut in the public demonstration of IGES translators. There are now 17 vendor implementations of this key interface specification.

Recent events have seen the adoption of IGES by the US Navy as well as its inclusion as a mandatory item in procurement requests from General Motors and incorporation as the means for product data exchange in NASA's Space Station Definition contract.

Leonard Haynes has been selected to be Chairman of Subcommittee R15.04 "Communications and Information" of the Standards Committee of the Robot Industries Association.

Leonard Haynes has been selected to be Chairman of the Standards Committee for the IEEE Robotics and Automation Council, the coordinating and focal point for all IEEE efforts related to standards for robotics.

Victor Nedzelnitsky was appointed as technical advisor for the U.S. National Committee of the International Electrotechnical Commission (USNC/IEC, a committee of the American National Standards Institute, ) for Technical Committee 29 "Measuring Devices" (SC 29C). The activities of IEC TC 29 and subgroups include those fundamental areas of precision electroacoustic measurements in which NBS is currently active, as well as numerous others. Responsibilities of this advisory position include chairing the U.S. delegation to international meetings of IEC TC 29, its subcommittees and approximately 20 working groups, designating persons (usually chairmen of corresponding U.S. ANSI working groups) to solicit and coordinate U.S. comments on documents produced by IEC TC 29 and its subgroups. The U.S. Technical Advisor to USNC/IEC also serves as an ex officio member (nonvoting) of the Acoustical Society of America (ASACOS). 
Three draft MIL-Standards on ultrasonic and acoustic emission test techniques have been prepared by CME for the Army Mechanics and Materials Research Center, the preparing organization for NDE military standards. The standards are coordinated with the Navy and Air Force. The draft standards are the "Primary Calibration of Acoustic Emission Transducers", "Glossary of Terms and Def initions for Acoustic Emission Testing Procedures" and "Glossary of Terms and Definitions for Ultrasonic Testing Procedures". The standards are based on CME research and expertise in ultrasonic standards.

Nelson Hsu received the Acoustic Emission Working Group (AEWG) Achievement Award in Apri1. The award was given for his "creative invention and development of the pencil lead-break simulated acoustic emission detection systems." The pencil source is a calibration tool is being written into MIL-Standards, ASTM Standards, Society of Plastics Industries (SPI) standards and European Working Group on Acoustic Emission standards.

"A Preliminary Proposal for Franco-American Cooperation in Surface Finish Technology" was recently developed by a group of French and American scientists and engineers including Theodore Vorburger, CME, Prof. J. Bielle of ENSAM in Chalons sur Marne, J. P. Letouzey, Scientific Attache at the Embassy of France, and F. Parsons and A. Tabenkin of Federal Products Corporation. The proposal calls for the establishment of a joint Franco-American Data Bank for the Surfaces of Mechanical Parts. The data bank will enable surface texture information critical to the operation and wear of mechanical devices, such as automobiles and aircraft, to be shared by engineers and industrialists. The proposal was the culmination of a technical exchange between French and American experts in Surface Metrology and calls for research to explore the relationships between the very different French and American standards in this area. The above working group presented the proposal to ANSI Standards Committee B46 on the Classification and Designation of Surface Qualities on March 28, 1984. The committee then agreed to champion the proposal, and an informal committee headed by Vorberger was formed to begin the organization process.

Polystyrene microspheres made on the NASA Space Shuttle will be dimensionally characterized by a team of NBS scientists led by Thomas Lettieri. The microspheres will be the third in a series of particle sizing standards developed through a joint NBS/ASTM program under the direction of the ASTM S-21 Committee for Standard Reference Materials for Particle Metrology. The Bureau scientists are working with a group at Lehigh University, which developed and now oversees the chemical process for manufacturing the microspheres aboard the Space Shuttle. Because of the near absence of gravity, the particles made in space are much more spherical and uniform in size than similar particles made on earth. These qualities make the Shuttle microspheres extremely attractive as a Standard Reference Material for calibrating such instruments as blood cell counters, optical microscopes, and aerosol measuring instruments. 
Since 1976, the Department of Energy has sponsored research at the NBS and other national laboratories to aid in the development of test methods and standards for active solar heating and cooling systems. During 1984, NBS published NBSIR 84-2845, "Test Methods and Standards Development for Active Solar Heating and Cooling Systems". The report documents the research and resulting consensus standards for solar domestic hot water systems, solar collectors, thermal storage devices and solar collector materials. For solar collectors, it gives a detailed description of the standards and test methods for cover plates, absorber materials, collector insulation, gaskets and sealants, rubber hose, containments materials, and heat transfer fluids.

The Energy Policy and Conservation Act (Public Law 94-163) and the National Energy Conservation Policy Act (Public Law 95-619) required the Department of Energy to prescribe testing and rating procedures as well as minimum performance standards for the major energy consuming appliances in residential buildings. The responsibility for developing the testing and rating procedures for central heating and cooling equipment was assigned to NBS and has been a major element of the Centers's program for the past 8 years. During 1984, the American Society of Heating, Refrigerating, and Air Conditioning Engineers (ASHRAE) maintained a Standards Committee to manage over 60 of the Societies' technical project comittees that revise and develop new standards for the testing of heating and air conditioning equipment. James Hill was elected Vice-Chairman of the Committee for 1984-1985.

The American Society of Heating, Refrigerating and Air Conditioning Engineers (ASHRAE) started a major revision of its ANSI/ASHRAE/IES Standard 90A-1980, "Energy Conservating in New Building Design." The original Standard 90 issued in 1975 was based on work done in CBT for national code officials. The 1980 Standard will be split to form two documents--one for large high-use commercial buildings and one for residential buildings. CBT has contributed to the standard for commercial buildings by developing recommendations to upgrade the 1980 standard using computer programs for analys is of energy use. The residential standard will be based on a report of recommendations of an Ad Hoc Committee chaired by Frank Powell. The new standards project committee for residential buildings is also chaired by Frank Powell.

The International Standards Organization (ISO) Technical Committee 163, on Thermal Insulation, has produced international standards on methods of measurement of thermal conductivity that are largely based on ASTM standards to which NBS has contributed for over 40 years. This committee also produced an infrared thermographic standard to which Richard Grot of NBS was a major contributor. Frank Powell of NBS is conducting an international round-robin on the thermal conductivity of insulation for ISO TC 163. Twenty-six countries are participating with 125 guarded hot plate and heat flow meter devices. 
Frank Powell was elected Chairman of ASTM Committee $\mathrm{C}-16$, on Thermal Insulation. $\mathrm{C}-16$ has about 345 members and is responsible for preparing and revising standards covering test methods, materials specifications and standard practice guidelines. $\mathrm{C}-16$ sponsored a major conference whose theme was controlling fuel costs through thermal insulation. Seventy papers were presented at the conference and the proceedings will be published as an ASTM Special Technical Publication (STP). Work in this field started at NBS in 1909 and NBS has actively contributed to this Committee for over 40 years. Frank Powell is the first NBS representative to be elected Chairman.

Past research performed by CBT has resulted in a draft ASTM standard on the application of the maturity method for predicting the in-place strength of concrete in new structures in order to assure safety during construction. The draft standard was successfully balloted in September by ASTM Subcommittee C09.02.05 on Nondestructive Testing of Concrete. Nicholas Carino was the task force chairman and principal author of the draft standard. CBT has also completed research on the pullout test method, another technique for measuring the in-place strength of concrete, and has submitted recommendations for revising the existing ASTM standard on this method. The recommendations should result in increased reliability of the strength predictions.

The American Society of Civil Engineers Technical Council on Codes and Standards elected James Gross to the Council Executive Committee. This Executive Committee provides oversight and guidance to all ASCE standards development activities. Currently eight major standards development activities are underway, two of which are Foundation and Excavation Standards chaired by Felix Yokel and Structural Condition Assessment of Existing Buildings chaired by James Pielert. Kyle Woodward is a member of the Committee on Masonry Structures Standards. NBS has recently transferred the responsibility for the secretariat for the ANSI Standard A58, "Design Loads on Buildings and Other Structures", to ASCE. This widely used standard was under the sponsorship of NBS for 60 years and is now the responsibility of ASCE. The voluntary consensus standards of ASCE are widely used for design guidance, procurement, and construction regulation.

The results of CBT's research on construction loads was the criteria used for establishing the design load provision in ANSI A 10.9, "Standards for Safety Requirements for Concrete Construction" and the ACI 347 Standards for Formwork. Hai Lew serves as the subcommittee chairman of the ANSI A 10.9 subcommittee which is responsible for drafting the standard. CBT carried out an extensive program to measure and document construction loads occuring on highrise concrete structures under construction. The design load requirements based on the load survey data would provide greater safety and economy in concrete construction.

During the past 5 years, CBT carried out a comprehensive research program on the strength gain characteristics of concrete at early ages and on methods of measuring in-place strength of concrete. The results of this research provided technical data for introduction of a new provision in ACI Building Code Requirements which allows the use of nondestructive test procedures to 
determine in-place strength of concrete for the purpose of reviewing the formwork. Hai Lew serves on ACI 318 Standard Committee and was responsible for providing the necessary data for the new provision.

Center for Fire Research (CFR)

CFR staff members were very active at meetings of the National Fire Protection Association throughout the year. A preliminary report of the NFPA Advisory Committee on the Toxicity of the Products of Combustion was presented by Chairman Jack Snell at the May meeting and published in the Fire Journal. As part of its responsibility for providing guidance and recommendations to NFPA Technical Committees, this group sponsored a workshop which focused on six specific applications where combustion product toxicity could be critical; several senior CFR scientists contributed. At the $1984 \mathrm{fall}$ meeting, CFR staff provided presentations and tutorials on smoke control design; fire detector spacing; and fire growth modeling. CFR staff are also providing revised chapters for the new edition of the NFPA Fire Protection Handbook, including chapters covering Fire Hazards of Materials, Building Construction, and Tables and Charts of physical and thermal properties.

In standards actions, a new Chapter 21 dealing with Residential Board and Care Occupancies (plus detailed Appendices F and G) was accepted as part of the NFPA 101 Life Safety Code; this is based on the CFR-developed Fire Safety Evaluation System which had previously been adopted for health care occupancies in the 1981 edition. Also accepted was the Fire Safety Evaluation System (FSES) for Detention and Correctional Occupancies (Chapters 14 and 15 and Appendix E of NFPA 101).

CFR staff members have also completed the development of a new Fire Safety Evaluation System for National Park Service overnight accomodations. This system, which identifies alternative combinations of fire protection systems and building design features that provide a level of fire safety equivalent to that prescribed by the Life Safety Code, was reported in NBSIR 84-2896.

James Winger and Sanford Davis have provided input to a newly formed NFPA Ad Hoc Subcommittee on Contents and Furnishings. In addition, CFR personnel are important contributors to subcommittees on furnishings, modeling, and rate of heat release of the NFPA Fire Test Committee, chaired by Sanford Davis. Revisions of several existing standards, including NFPA $260 \mathrm{~A}$

(Cigarette Ignition Resistance of Components of Upholstered Furniture) were based on CFR inputs. A proposed new standard, NFPA 264, for measuring rate of heat release using oxygen consumption calorimetry is based on the NBSdeveloped con calorimeter. This is also being pursued by a Task Group in ASTM E5.21 headed by Vytenis Babrauskas, and by a Working Group of ISO TC92 Subcommittee 1 on Reaction to Fire Tests. The apparatus and test details were initially described in NBSIR 82-2611. 
A newly formed Committee, NFPA 90S, has started work on a design standard for smoke control systems in buildings. John Klote serves as co-chairman.

Revision of NFPA 13D, incorporating technical findings on fast-response sprinklers originating in CFR, was approved. CFR personnel are also active in promoting U.S. innovations for evaluating the time response of conventional sprinkler head in the Working Group on Sprinkler Systems of ISO TC21 Subcommittee 5 (Fixed Fire Extinguishing Systems).

CFR-proposed revisions to the 1984 Standard for Chimney, Fireplace, Vents and Solid Fuel Burning Applicances (NFPA 211) were adopted. Information provided to the Committee will appear in NBS reports dealing with (a) clearances and methods for protecting exposed surfaces, and (b) thimble-chimney connector systems.

CFR staff members were also active at meetings of ASTM Committee E5 on Fire Standards. At the E5 Symposium on Application of Fire Science to Fire Engineering in Denver, seven of the 24 papers were presented by CFR staff and Research Associates.

CFR research has direct application to a variety of ASTM standard test methods. A new test method for "Critical Radiant Flux of Exposed Attic Floor Insulation Using a Radiant Heat Energy Source", ASTM E970, was officially promulgated. A report (NBSIR 84-2917) examined the effect on fire performance of the environmental cycling schedule prescribed in ASTM C739 for loose-fill cellulosic thermal insulation. Another study (NBSIR 84-2887) examined the use of ASTM D635 and other existing and proposed standard test methods for evaluating flame spread on combustible solar collector glazing materials. NBSIR 84-2876 reviewed the need and availability of standard test methods for measuring the smoke leakage characteristics of door assemblies. In NBS Technical Note 1193, Richard Peacock and Emil Braun provided an assessment of standard ASTM and NFPA laboratory test methods for flame spread, smoke, critical radiant flux and rate of heat release versus performance in full-scale mockup tests of Amtrak passenger rail vehicle interiors. John Krasny summarized the important thermal properties and fire test methods for fabrics in an international ASTM symposium on the performance of protective clothing. An extensive review and "white paper" on the ASTM E84 Steiner Tunnel Test was completed with major input from Bill Parker and is scheduled for publication in the ASTM Journal of Testing and Evaluation in early 1985.

A new standard reference material, SRM 1012, has been developed for use with the Flooring Radiant Panel Test, ASTM E648. The kraft paperboard SRM is certified to provide a critical radiant flux value of $0.36 \pm 0.04 \mathrm{~W} / \mathrm{cm}^{2}$ based on engineering testing and analysis by James Lawson.

Dan Gross participated as a technical expert in Working Group meetings of ISO TC92 Subcommittee 2 in Edinburgh Scotland. Active consideration is being given to updating current tests and formulating future fire resistance tests and calculation methods for structural components, fire and smoke control 
doors, ventilation ducts, roof covering, and barrier penetrations. Vytenis Babrauskas participated as a technical expert in Working Group meetings of Subcommittee 1 in Ludwigshaven, where he provided information and advice on the cone calorimeter method for rate of heat release plus other test methods for ignitability, flame spread and heat of combustion.

Barbara Levin has been appointed Chairperson of the U.S. Technical Advisory Group for ISO TC92 Subcommittee 3 on Toxic Hazards; this TAG is administered by ASTM as a task group in ASTM E5.34.

Sanford Davis has been appointed Chairman of the NFPA Fire Test Committee, which has responsibility for reviewing, maintaining and interpreting a dozen existing standard fire tests and developing new standard test methods.

\section{Center for Chemical Engineering (CCE)}

The thermophysical properties tables for propane contained in NBS Monograph 170 were adopted in April by the American Society for Testing and Materials and published as ASTM Standard D 4362. The monograph, authored by R. D. Goodwin and W. M. Haynes, is the culmination of a comprehensive research project on the thermophysical properties of propane.

ASTM C177 Guarded-Hot-Plate test method has been rewritten under the chairmanship of J.G. Hust. It has been ballotted by Subcommittee C16.30 and by Committee $\mathrm{C} 16$ in December. This revision represents a major change in a document that has caused considerable confusion in the past.

In addition, a new standard practice has been developed under the same task group. This new standard practice discusses the significance of derived property data obtained from thermal property test method data. The efforts of CCE in insulation research has been invaluable in the establishment of these new ASTM documents.

The CODATA task force on thermal properties of solids recently completed an extensive round-robin effort on the measurement of thermal and electrical properties of several reference materials. The specimens were selected from NBS/OSRM reference materials. Data were obtained for thermal conductivity, thermal diffusivity, specific heat, thermal expansion, and electrical resistivity over a wide temperature range ( 4 to $3000 \mathrm{~K}$ ). The materials involved were electrolytic iron, stainless steel, tungsten, and graphite. As one of the consequences of this program the SRM's were updated to include the new data. In addition, the data base on these materials has been considerably enhanced.

Another output from this project is the establishment of standard reference data for four metals over a wide temperature range (2 to $3000 \mathrm{~K}$ ). The metals 
involved are copper, aluminum, iron and tungsten. J. G. Hust is a member of this CODATA task force and performed the analysis for both of these projects.

The procedures developed by Jane E. Callahan and Sandra A. Sullivan for heat capacity measurements and for making pan corrections with the Differential Scanning Calorimeter were documented and forwarded to the Subcommittee on Test Methods and Practices of E37 "Thermal Methods", ASTM, at their request. This information was subsequently incorporated into the present revision of a Standard Test Method for Determining Specific heat Capacity by Differential Scanning Calorimetry. Dr. Callahan's laboratory was one of five participating in a round-robin conducted to evaluate this revised Standard Test Method.

A number of ASME flow measurement standards are being initiated or are being revised in conjunction with NBS fluid metering programs. These ref lect the increasingly wide range of interests in more accurate fluid quantity and flowrate measurements in fluid process control situations and in custody transfer of valuable fluid resources and products. Specifically, in the ASME Committee on the Measurement of Fluid Flow in closed conduit (MFFCC) an Ad Hoc Subcommittee on Vortex Shredding Flowmeters has been formed to prepare a standard entitled "Vortex Shedding Flowmeters". This effort was in itiated in late 1983 in conjunction with in industry-government consortium formed at NBS-Gaithersburg in January 1984 to conduct an industry-government designed research program on "jitter and fade" phenomena, which perturb the performance characteristics of vortex shedding flowmeters. The results of this NBS consortium program are being used to guide the content of this document scheduled for Committee review in early 1985. NBS staff members G. E. Mattingly and B. Robertson are conducting the consortium-funded research; G. E. Mattingly serves as chairman of the ASME Subcommittee. 


\section{AWARDS}

The Edward Bennett Rosa Award recognizes outstanding achievements in the development of meaningful and significant standards of practice in the measurement field. The award is named after Dr. Edward B. Rosa, a physicist who set the pace for high level achievement in the early years of the Bureau. The following NBS staff members received this award in 1984:

Bradford Smith was selected for his outstanding achievements and leadership in the development of the Initial Graphics Excharige Specification (IGES). This standard has been developed, formalized, approved by ANSI, and implemented by every major vendor of CAD/CAM systems within its short five-year history. It has been adopted by use by such users as General Motors, the U.S. Navy, Hughes Aircraft, Boeing, NASA, and the Department of Defense.

Dr. John F. Heafner was cited for his leadership and technical role in the development of the transport protocol standard for computer networks and associated measurement methadologies. The transport protocol is a key network protocol. Dr. Heafner directed the development of formal description techniques to define networking standards and a set of innovative measurement methodologies to measure their performance and correctness.

The Silver Medal Award is bestowed for "meritorious contributions of unusual value to the Department of Commerce." The following NBS staff member received a silver medal award in 1984 for standards related activities:

George W. Burns (NEL) for his outstanding contribution to standards activities concerning the measurement of temperature using thermacouples. 

APPENDIX I - NBS FORM 83 

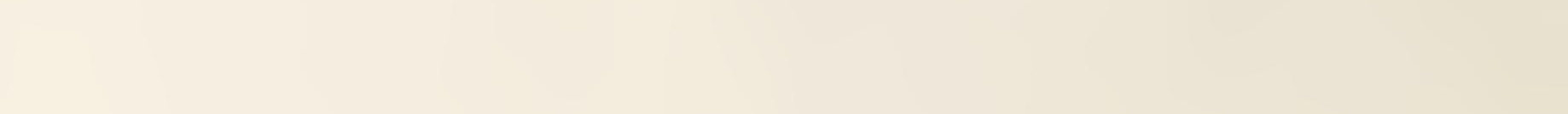


\begin{tabular}{|c|c|c|c|}
\hline $\begin{array}{l}\text { NBS.83 } \\
\text { (Aev. 10-80) }\end{array}$ & O.8. DEP/ & $\begin{array}{l}\text { JT OF COMMERCE } \\
\text { Uumau of } 8 \text { tandards }\end{array}$ & $\begin{array}{l}\text { SEE REVERSE SIDE FOR } \\
\text { INSTRUCTIONS }\end{array}$ \\
\hline \multicolumn{4}{|l|}{ PE OR PRINT Y } \\
\hline $\begin{array}{l}\text { 1. Purpose: } \\
(" x " \text { one) }\end{array}$ & $\begin{array}{l}\square \text { CHANGE INFORMATION PREVIOUSLY } \\
\text { SUBMITTED }\end{array}$ & \multicolumn{2}{|c|}{$\begin{array}{l}\square \text { TERMINATION OF MEMBERSHIP } \\
\text { (COMPLETE BLOCKS } 1 \text { - } 9 \text { ONLY) }\end{array}$} \\
\hline \multirow[t]{2}{*}{ 2. Name (lost, first, initian } & 3. Org & onal Code Number & 4. Da:e \\
\hline & $\begin{array}{l}\text { 5. NB. } \\
\text { BLDG. }\end{array}$ & $\begin{array}{l}\text { ng Address } \\
\text { ROOM }\end{array}$ & 6. NBS Telephone Ext. \\
\hline
\end{tabular}

7. NBS Employment Status:

$\square$ FULL-TIME PERMANENT $\square$ ANNUITANT $\square$ OTHER (specify)

8A. This form covers the following assignment: LEVEL (" $x$ " one)

$\square$ PARENT COMMITTEE

NUMBER (if applicable)

COMPLETE NAME OF ACTIVITY

$\square$ SUBCOMMITTEE

$\square$ TASK OR WORK GROUP

$\square$ OTHER (specify)

8B. If $8 \mathrm{~A}$ is a parent committee go to No. 9 . If $8 \mathrm{~A}$ is a subgroup of a committee (e.g., a subcommittee or task group) list the higher levels below:

\begin{tabular}{|l|l|l|} 
LEVEL & NUMBER & \\
PARENT COMMTTEE & & \\
\hline SUBCOMMITTEE & & \\
\hline OTHER (specify) & & \\
\hline
\end{tabular}

9. Parent Organization

11. Date of Assignment (month/year)

13A. Type of Committee (base classification on type of committee, not organization) (" $x$ " one):

\begin{tabular}{|l|l|l|l|}
\hline NATL & "NATL/INTL & INTL & \\
\hline & & & \\
\hline & & & \\
\hline & & & \\
\hline & & \\
\hline & & \\
\hline
\end{tabular}
14. Position on Committee (" $x$ " one):
D MEMBER
$\square$ TECHNICAL ADVISOR
$\square$ CHAIR
$\square$ VICE-CHAIR
$\square$ ALTERNATE REPRESENTATIVE
D SECRETARY
$\square$ DELEGATE
$\square$ OTHER (specify)

15. Voting Status (" $x$ " one):
[] VOTING
$\square$ NONVOTING
17. Key Words (FOR USE BY COMMITTEE MONITORING OFFICE)

10. Secretariat Organization or Country (if different from parent organization)

12. Expiration Date of Assignment (if any)

13B. "Nat'I Committee with Major Internat'I Responsibilities

IF YOU CHECKED NATUINTL, PLEASE SPECIFY THE INTERNATIONAL COMMITTEE OR COMMITTEES WITH WHICH THE NATIONAL COM. MITTEE IS CONCERNED:

COMPLETE NAME 


\section{INSTRUCTIONS}

\section{INTRODUCTION}

This form serves as a record of management approval of committee activities and provides basic information whlch is used to compile a directory of standards committee participants and a series of special reports for NBS managers and committee participants. For further information, including definitions of terms used on this form, reference Administrative Manual Subchapter 3.02 on Standards and Professional Committees. Any questions or suggestions for improving this form should be directed to the Office of Standards Information, Analysis and Development (Division 781), which serves as the NBS Committee Monitoring Office, Technology Building, Room B-166, extension 2092.

\section{GENERAL INFORMATION}

1. A separate form should be completed for each committee. For example, if you belong to a committee and two of its subcommittees, three forms should be filled out.

2. A form should be filed as soon as possible after joining or applying for membership on a committee. Employees are responsible for completing and returning to the committee or parent organization any forms they require.

3. Additional forms should be filed to indicate changes to the original form, to renew expired memberships, and to record resignations. Forms need not be filed for internal NBS committees.

4. Copies for distribution: the original and two copies of the form are to be sent to the designated individuals for approval (see Approvals).

\section{SPECIFIC COMMENTS}

Blocks 1 - 6 - Minor changes such as phone extension or mailing address may be made by notifying the Committee Monitoring Office by phone (x2092) or memo (Technology Building, B-166). If you are resigning from a committee, complete only Blocks 1 - 9 .

Block 10 - Name of an organization or country only, not an individual.

Block 11 . If you have been accredited as a delegate to a specific meeting, put the starting date of the meeting in this block. If you have been asked to serve as a delegate for an indefinite period of time, put the date you accepted the assignment in this block.

Block 13A - Interagency Committee means a committee composed wholly of employees of two or more Federal Government agencies.

Public Advisory Committee means any committee that is 1) established by Federal statute or reorganization plan; 2) established or utilized by the President; or 3) established or utilized by one or more agencies to obtain advice or recommendations for the President or for one or more Federal Government agencies. The term does not include any committee which is composed wholly of employees of the Federal Government.

Block 14 - Indicate your current position on the activity listed in Block 8A. If you serve in more than one capacity, check only the highest position held.

Block 16 - Indicate the organization which pays for your time, travel, or other expenses when you are involved in committee work.

\section{Block 17 - DO NOT FILL OUT. FOR COMMITTEE MONITORING OFFICE USE ONLY.}

APPROVALS (For further explanation of the types of representation, reference Administrative Manual Subchapter 3.02, Standards and Professional Committees.)

Block 18 - 1) If an NBS technical representative - Send the original and two copies of the NBS-83 to the Division Chief or higher for approval. Division Chiefs and higher level managers should sign their own forms. After approval is obtained, send the form to the Office of Standards Information, Analysis and Development, which serves as the NBS Committee Monitoring Office, for processing.

2) If an official NBS spokesperson - Send the original and two copies of the NBS-83 with a cover memo explaining the assignment through the Division/Center office to the MOU Director for approval. After approval, the MOU Director forwards the material to the Office of Standards Information. Analysis and Development, which serves as the NBS Committee Monitoring Office, for review and forwarding to the Director.

NOTE TO SIGNERS: Your signature indicates that:

1) the activity is directly related to the authorized functions of NBS;

2) the appointee is qualified and can devote enough time and effort to serve creditably; and

3) there are adequate resources available or in prospect to support meaningful participation. 
APPENDIX II - LIST OF ACRONYMS/ABBREVIATIONS 



\section{ACRONYMS AND ABBREVIATIONS}

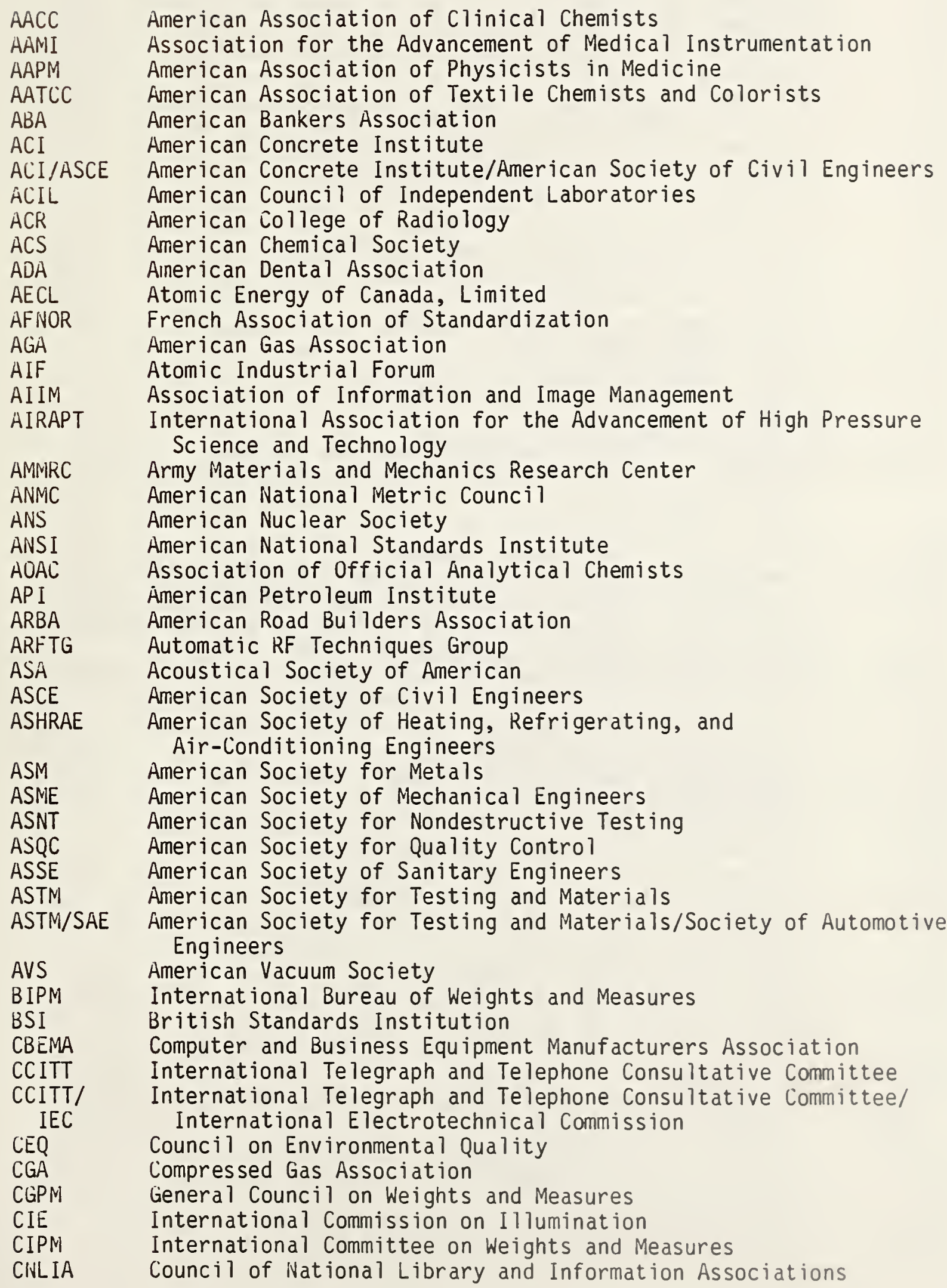


CUDASYL Conference on Data Systems Languages

CODATA Committee on Data for Science and Technology

DIN

DOC

DOD

DOE

DOI

DON

DOS

ECCB

ECMA

ECSA

EIA

EPA

ETPC

FAA

FDA

FEMA

FPA

GATT

GOST

GWI

HHS

HHS/FDA

German Institute for Standardization

Department of Commerce, U.S.

Department of Defense, U.S.

Department of Energy, U.S.

Department of Interior, U.S.

Department of the Navy, U.S.

Department of State, U.S.

Electronic Components Certification Board

European Computer Manufacturers Association

Exchange Carriers Standards Association

Electronic Industries Association

Environmental Protection Agency

European Thermophysical Properties Committee

Federal Aviation Administration

Food and Drug Administration

Federal Emergency Management Agency

Federal Preparedness Agency

General Agreement on Tarriff and Trade

State Committee for Standards of USSR

Grinding Whee 1 Institute

Department of Health and Human Services, U.S.

HPS

IAEA

IAEA/WHO

IAPS

ICRU

ICSU

Department of Health and Human Services, U.S./Food and Drug Administration

Health Physics Society

ICUMSA

IEC

IEEE

IES

IFCC

IIW

ILAC

IMEKO

IMO

INMM

ISA

ISO

ISR

ITU

IUCR

IUPAC

$J C P$

JCPDS-

ICUD

JEDEC

JIS

International Atomic Energy Agency

International Atomic Energy Agency/World Health Organization

International Association for the Properties of Steam

International Commission on Radiation Units and Measurements

International Council of Scientific Unions

International Commission for Uniform Methods of Sugar Analysis

International Electrotechnical Commission

Institute of Electrical and Electronic Engineers

Illuminating Engineering Society

International Federation of Clinical Chemistry

International Institute of Welding

International Laboratory Accreditation Conference

International Measurement Confederation

International Maritime Organization

Institute of Nuclear Materials Management

Instrument Society of America

International Organization for Standardization

International Society of Radiology

International Telecommunications Union

International Union of Crystallography

International Union of Pure and Applied Chemistry

Joint Committee on Printing

Joint Committee on Powder Diffraction Standards-International

Centre for Diffraction Data

Joint Electron Devices Engineering Council

Japanese Industrial Standards

MPC

Metal Properties Council

NACE

National Association of Corrosion Engineers

NAPM

National Association of Photographic Manufacturers 
National Academy of Sciences

NAS/NRC National Academy of Sciences/National Research Council

NASA

NBS

National Aeronautics and Space Administration

NCCLS

NCRP

NCS

NDE

NEMA

NFPA

NMA

NNDC

NRC

NSC

UIML

OMB

OPE I

PPEMA

RILEM

RILEM/

CIB

RTCA

SAE

SAMA

SEMI

SFPE

SNM

TAPPI

TDCC

UK

UN

UNECE

UNESCO

UNIDO

US

USCC

USCG

USGS

USNC/CIE

National Bureau of Standards

National Committee for Clinical Laboratory Standards

National Council on Radiation Protection and Measurements

National Communications Systems

Nondestructive Evaluation

National Electrical Manufacturers Association

National Fire Protection Association

National Micrographic Association

National Nuclear Data Center

National Research Council

National Safety Council

International Organization of Legal Metrology

Office of Management and Budget

Outdoor Power Equipment Institute

Portable Power Equipment Manufacturers Association (formerly Chain Saw Manufacturers Association (CSMA))

International Union of Testing and Research Laboratories for Materials and Structures

International Union of Testing and Research Laboratories for Materials and Structures/International Council for Building Research, Studies and Documentation

Radio Technical Commission for Aeronautics

Society of Automotive Engineers

Scientific Apparatus Makers Association

Semiconductor Equipment and Materials Institute

Society of Fire Protection Engineers

Society of Nuclear Medicine

Technical Association of the Pulp and Paper Industry

Transportation Data Coordinating Committee

United Kingdom

United Nations

United Nations Economic Commission for Europe

United Nations Educational, Scientific and Cultural Organization

United Nations Industrial Development Organization

United States

U.S. Calorimetry Conference

U.S. Coast Guard

U.S. Geological Survey

USNC/

ICUMSA

USNC/IEC

U.S. National Committee/International Commission on Illumination

USNC/ITU

USNWG/

OIML

USPC

USSR

WRC

U.S. National Committee/International Commission for Uniform Methods of Sugar Analysis

U.S. National Committee/International Electrotechnical Commission

U.S. National Committee/International Telecommunications Union

U.S. National Working Group/ International Organization of Legal Metrology

U.S. Pharmacopeial Convention, Inc. Union of Soviet Socialist Republics Welding Research Council 
NBS-114A (REV. 2-80)

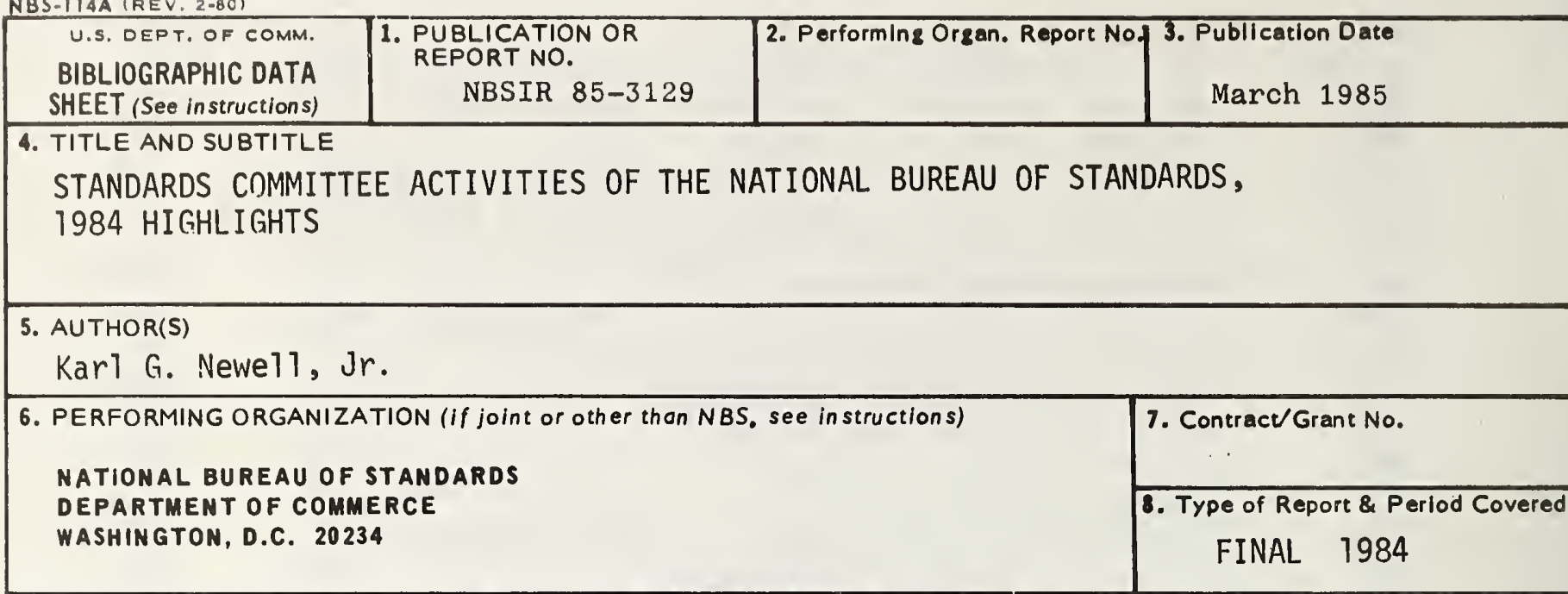

9. SPONSORING ORGANIZATION NAME AND COMPLETE ADDRESS (Street, City. Stote, ZiP)

10. SUPPLEMENTARY NOTES

Document describes a computer program; SF-185, FIPS Software Summary, Is attached.

11. ABSTRACT (A 200-word or iess factual summary of most significant information. If document includes a significant bibiiography or literature survey, mention it here)

This report summarizes NBS standards committee activities and accomplishments during calendar year 1984. It profiles NBS staff participation on outside standards committees and highlights significant technical and individual contributions made by NBS staff. In 1984, 444 staff members (or $28 \%$ of NBS' professional, scientific, and technical staff) participated in 1,138 committees of 89 national and international standards organizations.

12. KEY WORDS (Six to twelve entries; olphabetical order; copitalize only proper names; and separate key words by semicolons) Annual report; committee particination; standards committees; voluntary standards. 20402.

14. NO. OF PRINTED PAGES

X] Order From National Technical Information Service (NTIS), Springfield, VA. 2216I

\section{1}

15. Price 

